\title{
Review Article \\ Receptor Function and Response of Semiconductor Gas Sensor
}

\author{
Noboru Yamazoe and Kengo Shimanoe \\ Faculty of Engineering Sciences, Kyushu University, 6-1 Kasuga-koen, Kasuga, Fukuoka 816-8580, Japan \\ Correspondence should be addressed to Kengo Shimanoe, simanoe@mm.kyushu-u.ac.jp
}

Received 27 March 2009; Revised 27 March 2009; Accepted 19 April 2009

Recommended by Michele Penza

Theoretical approaches to receptor function and response of semiconductor gas sensor are described, following the illustrations of some relevant key issues such as tunneling transport. Depletion in small semiconductor crystals is characterized by the occurrence of new type depletion (volume depletion) after conventional one (regional depletion), and inclusion of both types makes it possible to formulate the receptor function and response to oxygen (air base), oxidizing gas (nitrogen dioxide), and reducing gas (hydrogen). The equations derived theoretically using physical parameters of the semiconductor side and chemical parameters of the gases side appear to reproduce satisfactorily the sensing behavior to the aforementioned gases as well as the influence of changes in physical parameters such as grain size and donor density. Extension to the semiconductor crystals dispersed with surface electron-traps shows that the traps act as a sensitizer to promote sensor response.

Copyright (c) 2009 N. Yamazoe and K. Shimanoe. This is an open access article distributed under the Creative Commons Attribution License, which permits unrestricted use, distribution, and reproduction in any medium, provided the original work is properly cited.

\section{Introduction}

A semiconductor gas sensor (called device hereafter) possesses an electrical resistance made with a porous assembly of tiny crystals of an n-type metal oxide semiconductor, typically $\mathrm{SnO}_{2}, \mathrm{In}_{2} \mathrm{O}_{3}$, or $\mathrm{WO}_{3}$. The crystals are often loaded with a small amount of foreign substance (noble metals or their oxides) called a sensitizer. When operated at adequate temperature in air, the resistor changes its resistance sharply on contact with a small concentration of reducing gas or oxidizing gas, enabling us to know the concentration from the resistance change. For its inauguration with a report by Seiyama et al. [1] and a patent by Taguchi [2], this group of sensors has been subjected to a tremendous amount of R\&D efforts world wide aiming at improvements of sensing performances and extensions to new applications. Thanks to these researches, the group not only has grown to provide important tools to detect and/or control gases in places in modern society but also has pioneered to founding a new technology field where the devices are called chemical sensors. Speaking more exactly, semiconductor gas sensors have been classified into two subtypes, that is, surfacesensitive type operating at temperatures below $500^{\circ} \mathrm{C}$ and bulk-sensitive one operating at high temperature (typically at $800^{\circ} \mathrm{C}$ ) [3]. This article is concerned with those of the former type only.

Apart from such remarkable achievements in practical applications, basic understandings of this group of sensors have hardly been satisfactory, despite tremendous efforts of so many researchers as summarized in reviews [5-8]. This is partly because there are many complex factors which affect sensing properties. Not only the selection of a proper oxide semiconductor is important but also the methods and conditions for fabricating sensor devices exert profound influences on gas sensing properties through changes in donor density, crystallite size, contacting geometry between crystals, packing density (or porosity), packing thickness, and so on [7]. In addition, the sensing properties are often modified largely with loading with foreign substances such as sensitizers. Understandings of these phenomena indeed have required interdisciplinary knowledge among semiconductor physics, surface chemistry, solid-state chemistry, and so on. In order to facilitate the understandings, we have proposed to assume that the sensing properties are determined by three main factors, that is, receptor function, transducer function, and utility factor, as schematically shown in Figure 1 [4]. The first factor is concerned with how each constituent crystal responds to the surrounding atmosphere 


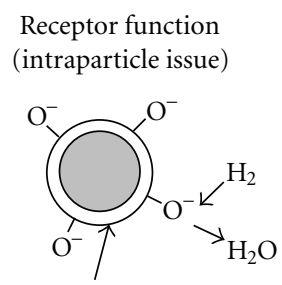

Space charge layer
Transducer function (interparticle issue)

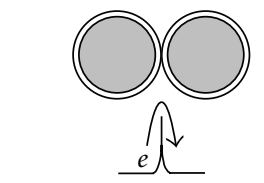

Double Schottky barrier (?)
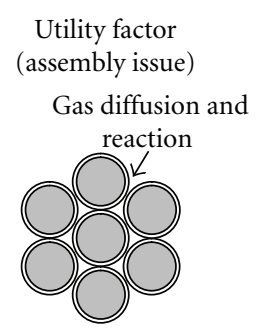

FIgURE 1: Three factors determining the response of semiconductor gas sensors [4].

containing oxygen and target gases (intraparticle issue). It is unanimous that oxygen is adsorbed on the crystals as negatively charged species, accompanied by the formation of a depletion layer inside the crystals. The target gases disturb the equilibrium through being adsorbed competitively or reacting with the adsorbed oxygen. The foreign substances like sensitizers dispersed on the crystals are assumed to affect these processes anyhow. The second factor is concerned with how the response of each particle is transformed into that of the whole device, and apparently this is related with the mechanism of electron transport between adjacent crystals (inter-particle issue). For a long time a double Schottky barrier model [9], which assumes migration transport of electrons over the barrier as shown, has been advocated for this process without critical check. The third one is concerned with the attenuation of the response due to the effect of diffusion and reaction of reactive target gases through the pores of the assembly of crystals (assembly issue) [10-12]. The above scheme has explained rather well qualitative nature of semiconductor gas sensors in several respects. However, it has failed to give quantitative understandings and, most importantly, to give new insights leading to innovations of this group of sensors. There should have been some serious defaults included in the scheme, particularly regarding the receptor and transducer functions.

Fortunately, we encountered an interesting finding several years ago that thin film devices fabricated from hydrothermally prepared colloidal suspensions of $\mathrm{SnO}_{2}$ by a spin-coating technique showed temperature-almost independent resistances in air in the temperature range 150 $400^{\circ} \mathrm{C}$, as shown in Figure 2 [13]. Such thermal behavior of resistances is hardly consistent with the double Schottky barrier model mentioned above. Instead, tunneling transport of electrons across the contacts (or gaps) between adjacent crystals is strongly suggested. In addition, this transport mechanism has made much easier the theoretical modeling of receptor and transducer functions recently carried out [14-16], because the constituent crystals can now be treated independently from each other. As revealed during this process, depletion in small crystals easily goes beyond conventional one (regional depletion) to enter new type one (volume depletion). Obviously, it is a lack of such information that has delayed fundamental understandings of this group of sensors, for most of their valuable gas sensing properties show up in the stage of volume depletion or nearby.

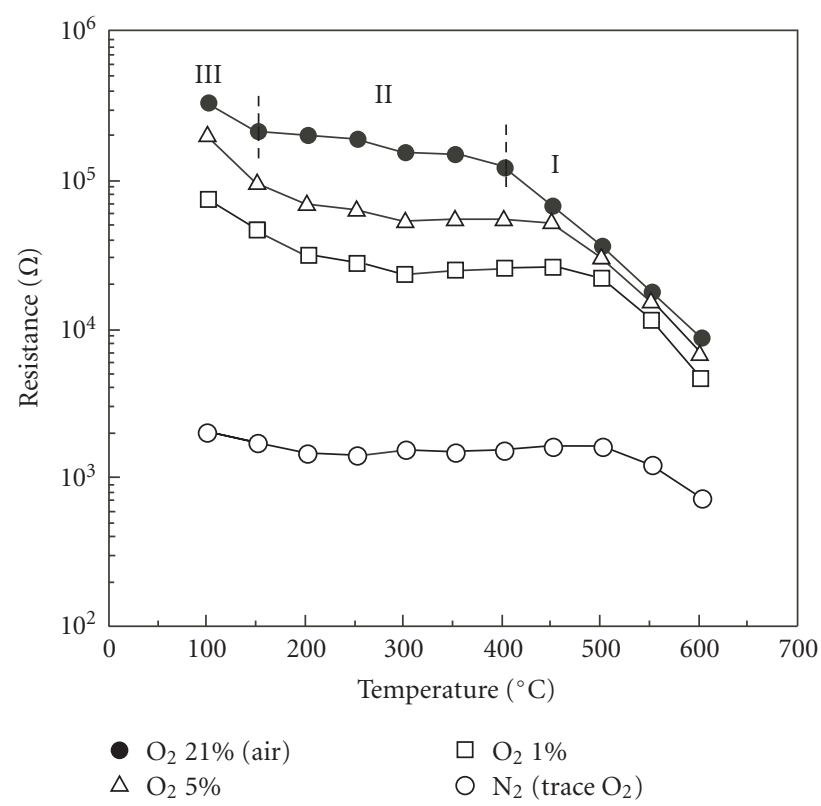

FIGURE 2: Resistance of device under selected partial pressures of oxygen as measured at various temperatures (spin-coated $\mathrm{SnO}_{2}$ thin film) [13].

In this review, we try to describe our theoretical approaches to semiconductor gas sensors. After brief descriptions of some experimental facts theoretically important, how to formulate receptor function and response of large and small constituent crystals to oxygen, nitrogen dioxide, and hydrogen is described to sufficient details followed by the comparisons with some experimental data. Also included is a recent extension [17] carried out to understand the sensitizing effects exerted by electron-accepting substances.

\section{Key Issues about $\mathrm{SnO}_{2}$ Gas Sensors}

2.1. Oxygen Adsorption on $\mathrm{SnO}_{2}$. The adsorption of oxygen on single-metal oxides was investigated by using a TPD technique by Iwamoto about 40 years ago [18]. He classified the transition of metal oxides into three groups depending on whether the amount of oxygen adsorbed and desorbed reversibly in the temperature range between room temperature and $500^{\circ} \mathrm{C}$ was large (Group A), small (B), or nondetectable (C). Group A consisted of p-type oxides, whereas some of n-type oxides such as $\mathrm{SnO}_{2}, \mathrm{ZnO}$, and 


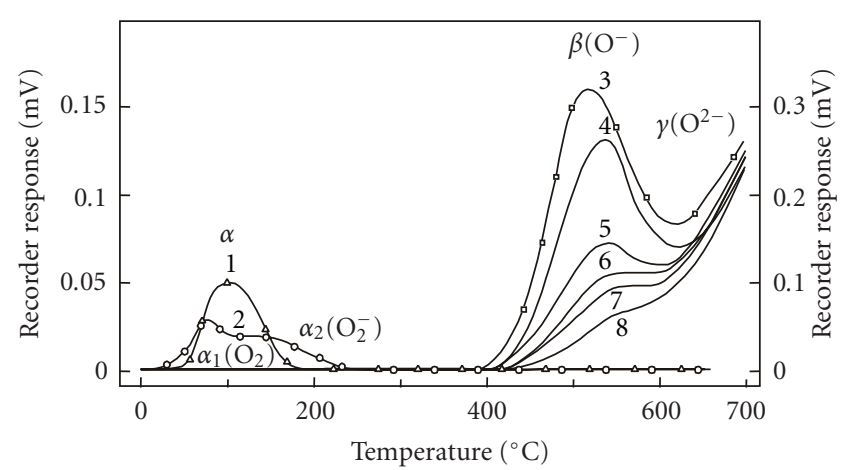

$\mathrm{O}_{2}$ adsorption
1 R.T., 94 Torr
$2155^{\circ} \mathrm{C} \rightarrow \mathrm{R} . T$. 100 Torr
$3 \sim 8400^{\circ}$ C, $99 \sim 2$ Torr

FIgURE 3: TPD chromatograms of oxygen desorbed from $\mathrm{SnO}_{2}$ [19].

$\mathrm{In}_{2} \mathrm{O}_{3}$ belonged to $\mathrm{B}$, and the others such as $\mathrm{WO}_{3}$ and $\mathrm{V}_{2} \mathrm{O}_{5}$ belonged to C. It is suggestive that Group B consists of typical oxides used for semiconductor gas sensors.

Oxygen adsorption on $\mathrm{SnO}_{2}$ was investigated in more detail by our group, also by using the TPD technique but for an extended temperature range up to $600^{\circ} \mathrm{C}$. The results are shown in Figure 3 [19]. There are four types of oxygen, $\alpha_{1}, \alpha_{2}, \beta$, and $\gamma$, recognized to be desorbed from $\mathrm{SnO}_{2}$ altogether. Of these, only the last two types, $\beta$ (presumably $\mathrm{O}^{-}$) and $\gamma$ (lattice oxygen $\mathrm{O}^{2-}$ ), are desorbed in the temperature range above $400^{\circ} \mathrm{C}$ after oxygen has been adsorbed during cooling from $600^{\circ} \mathrm{C}$ or at a fixed temperature of $400^{\circ} \mathrm{C}$. On the other hand, after oxygen has been adsorbed in the lower temperature range (below $155^{\circ} \mathrm{C}$ ), only $\alpha_{1}$ (neutral molecular $\mathrm{O}_{2}$ ) and $\alpha_{2}$ (superoxide ion $\mathrm{O}_{2}^{-}$) are desorbed in the temperature range up to $250^{\circ} \mathrm{C}$. Clearly these molecular adsorbates are formed only when the other dissociated species are absent. Also it is clear that at usual sensor operating temperatures (typically 300 $\left.400^{\circ} \mathrm{C}\right) \beta$ species prevails on the $\mathrm{SnO}_{2}$ surface. The amount of adsorption of this species has been shown to be fairly small (less than $1 \%$ in surface coverage), suggesting that its adsorption is limited by the supply of electrons. Later, a report was published, which identified $\beta$ to $\mathrm{O}^{2-}$ [20]. This identification cannot fit well to the theoretical analysis of response to oxygen, however. So it is assumed to be $\mathrm{O}^{-}$in the following treatments.

2.2. Grain Size Effects. About twenty years ago, we explored experimental methods to prepare small grains (crystallites) of $\mathrm{SnO}_{2}$. During this study, we found remarkable grain size effects [21]. As shown in Figure 4, the resistances under air (base) as well as under exposure to $\mathrm{H}_{2}$ or $\mathrm{CO}$ in air, $R_{a}$ and $R_{g}$, respectively, were found to increase sharply as the grain size $\left(d_{m}\right)$ decreased beyond a critical value $\left(d_{c}\right)$, while the sensor response to $\mathrm{H}_{2}$ or $\mathrm{CO}, R_{a} / R_{g}$, also increased, though more gradually, as $d_{m}$ decreased. Intuitively we felt that the phenomena were associated with the completion

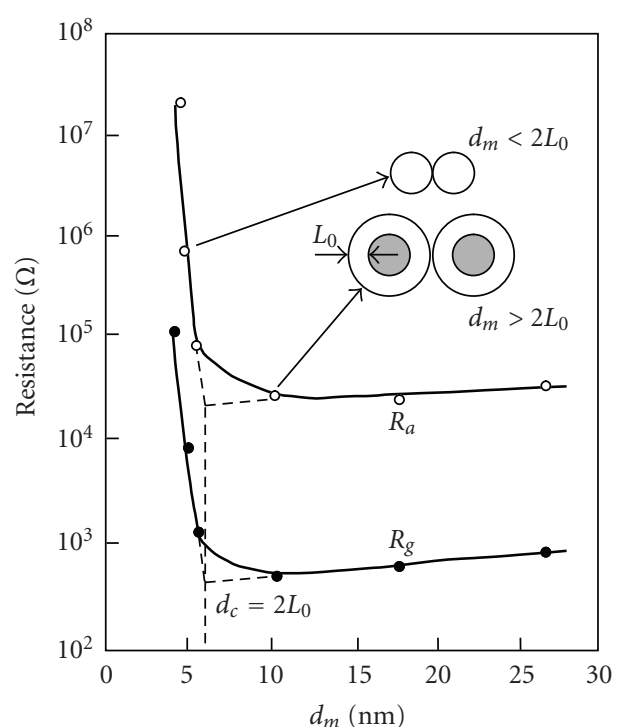

(a)

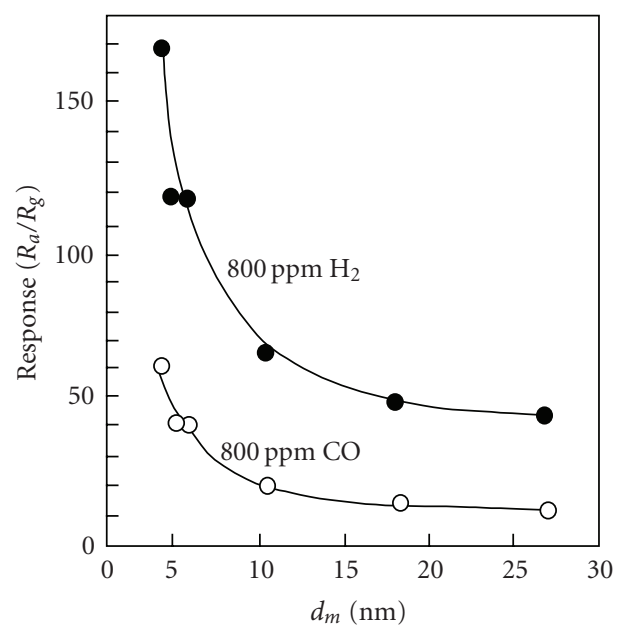

(b)

FIGURE 4: Grain size effects on resistance in air and sensor response to $\mathrm{H}_{2}$ or $\mathrm{CO}$ in air observed with $\mathrm{SnO}_{2}$ (brush-coated thick films) [21].

of depletion up to the whole region of constituent grains. Our interpretation (or assumption) was that $d_{c}$ would be coincident with twice the thickness of depletion depth and that decreasing $d_{m}$ beyond this point would be responsible for the sharp increases of $R_{a}, R_{g}$, and $R_{a} / R_{g}$ for some reasons yet unknown. Later, similar size effects were also observed for the response of lamellar or granular $\mathrm{WO}_{3}$-based devices to $\mathrm{NO}_{2}$, as shown in Figure 5 [22].

Although such grain size effects seemingly appeared to match well to the double Schottky barrier model, their real meanings were left open for a long time. Some researchers tried to explain the grain size effects [23-26]. Among them, Rothschild and Komen pointed out that the size effects could be explained as reflecting changes in the surface area/volume ratio of the constituent $\mathrm{SnO}_{2}$ grains $[23,24]$. Such situation 


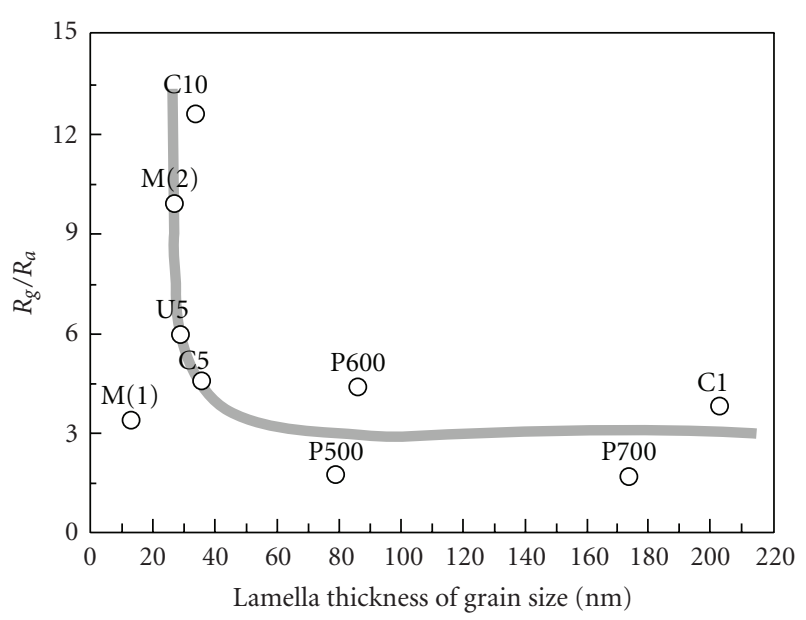

(a)

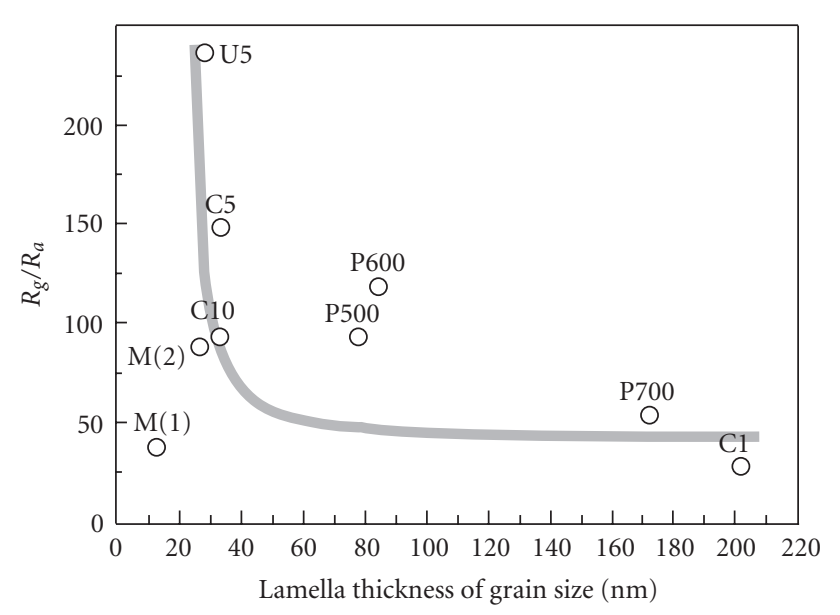

(b)

FIGURE 5: Sensor response to $1 \mathrm{ppm} \mathrm{NO}_{2}$ in air as correlated with granular size or lamellar thickness of constituent $\mathrm{WO}_{3}$ crystals [22]. The symbols attached indicate the preparation methods used for respective $\mathrm{WO}_{3}$ samples. See literature for details.

has turned out to appear typically in the stage of volume depletion in the present theory, as mentioned later.

2.3. Feasibility of Tunneling Transport. In sensor devices, constituent crystals are connected to adjacent ones either by contacts or by necks, the proportion of which depends on the methods and conditions of device fabrication. In case the device is fabricated through wet processes, the contact connections usually prevail, as seen in Figure 6 [13]. In such cases, it is easily understood that the device resistance is determined as a sum of the resistance of each contact. This idea has already been conceived in the double Schottky barrier model, which assumes that electrons migrate over the barrier at the contact. However, this model cannot be consistent with the temperature-almost-independent behavior shown in Figure 2, as already mentioned. From this consideration, we explored the possibility of tunneling transport of electrons [13]. The tunneling model used is

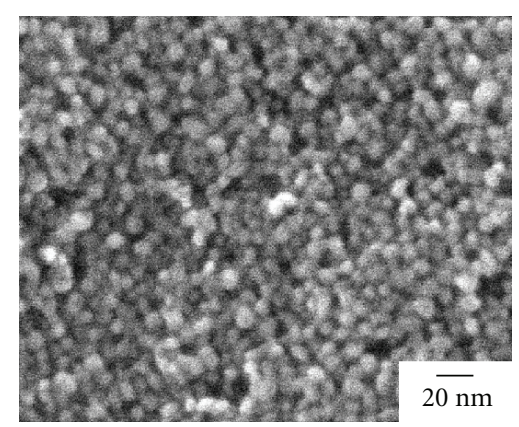

FIGURE 6: State of constituent grains as observed on SEM (spincoated $\mathrm{SnO}_{2}$ film) [13].

shown in Figure 7. The height of the wall to tunnel through is set to be equal to the electron affinity of the crystals, that is, the potential energy difference $(V)$ between the vacuum level and the conduction band edge at the surface, while the thickness is set to the gap $(L)$ between adjacent crystals. If $V$ is known, tunneling probability $(P)$ of an electron with energy $E$ above conduction band edge can be estimated as a function of $L$ by using a well-established equation. Reportedly, work function of $\mathrm{SnO}_{2}$ is dispersed between 4.7 and $5.7 \mathrm{eV}[27,28]$, while donor levels are shallow from conduction band edge. Therefore, $V$ takes a value of about $5.7 \mathrm{eV}$ at the maximum. The tunneling probability thus estimated assuming $V=6 \mathrm{eV}$ is shown in Figure 8. When the gap is zero (contact), $P$ is unity naturally regardless of $E$. $P$ decreases sharply with increasing $L$ and decreasing $E$, but notably it still keeps a significant value (.01 or above) at $L=0.1 \mathrm{~nm}$ and $E=0.03 \mathrm{eV}$. Considering that thermal energy is $51.7 \mathrm{meV}$ at $600 \mathrm{~K}$, it is understood that electrons can tunnel through such a gap with a significant probability. What this means is that electrons, exited thermally, can be transported by tunneling not only through the directly contacting region $(L=0)$ but also through a small gap in its vicinity, as schematically shown in Figure 9. It follows that even in the case of point contact (contacting area zero) electrons can be transported by tunneling but this is not the case by migration. As shown in Figure 7, $V$ is maintained at the same value in either of flat-band state (a) and bentband state (b). Therefore, the tunneling probability is kept the same in both, only the number of electrons involved being decreased with a progress of band bending. In this way, the tunneling mechanism is confirmed to be feasible well to the electron transport between adjacent crystals. There is no reason to exclude it. Rather it can even eliminate difficulties encountered by the migration mechanism.

2.4. Models of Electron Transport between Grains. The mechanism of electron transport between neighboring crystals is directly related with the transducer function of sensors. There are probably three representative models, as schematically drawn in Figure 10. Spherical crystals (uniform in size), connected with neighbors through a contact or a neck, are assumed to be depleted of electrons in the outer region only. Double Schottky barrier model (a) is a 


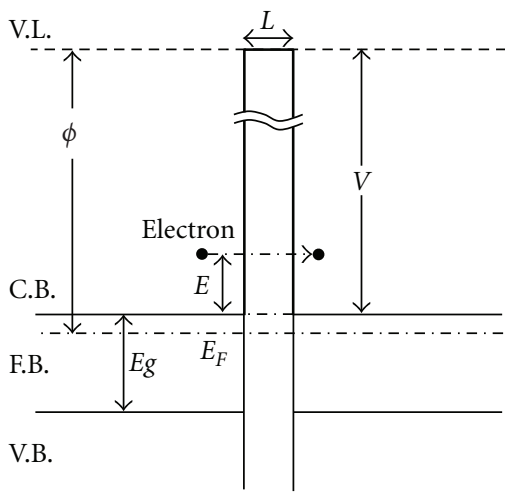

(a)

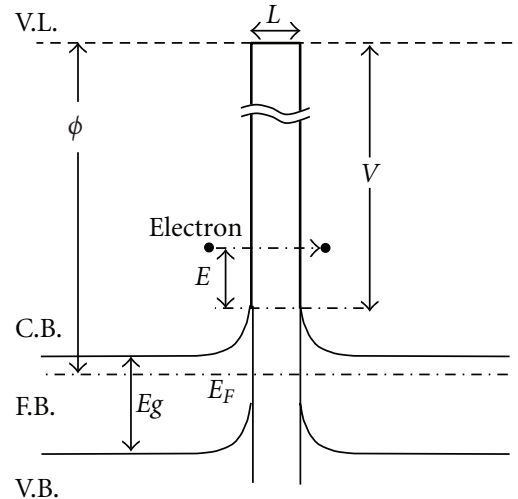

(b)

Figure 7: Model for electron tunneling across a gap between $\mathrm{SnO}_{2}$ grains [13]. (a) Flat band condition, (b) Bent band condition. V: Wall height V.L.: Vacuum level, C.B.: Conduction band, F.B.: Forbidden band, V.B.: Valence band.

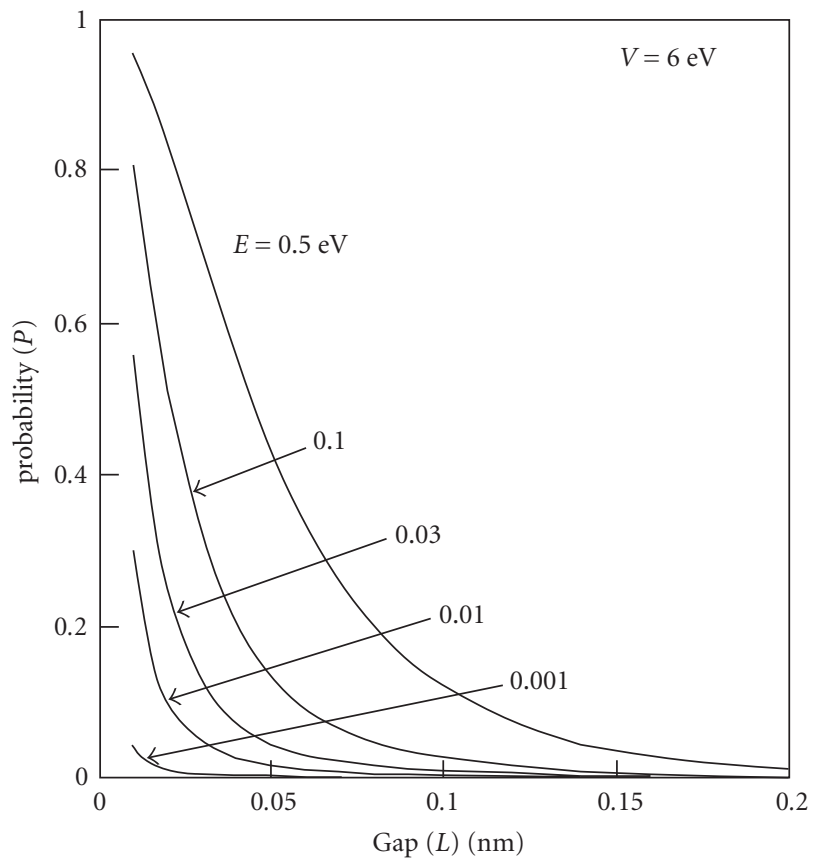

FIGURE 8: Tunneling probability calculated for various values of $E$ as a function of gap width $(L)[13]$.

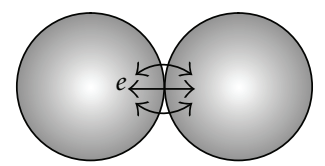

FIGURE 9: Schematic drawing of tunneling conduction across a gap between contacting spheres.

traditional one. It assumes that electrons are transported from nondepleted (core) region of one sphere to that of another by migration beyond a barrier in between. The barrier height not only determines the conductance of the contacting part but also gives rise to the activation energy of conduction on changing temperature. Tunneling transport model (b) assumes that electrons located at the periphery of one sphere are transported to that of another by tunneling through a small gap (typically $0-0.1 \mathrm{~nm}$ ) in between. The conductance is proportional to the density of electrons at the periphery, which is determined by the surface barrier height. On changing temperature, no activation energy is associated with the conductance provided that the barrier height is kept the same. Neck (or conduction channel) model (c) assumes that electrons migrate through a conduction channel which is formed by connecting the core regions of neighboring spheres. The channel width is narrowed at the neck parts so that the conductance is determined by the geometric relation between neck size and depletion depth. Of these models, (a) and (c), though looking likely at a glance, are not always free from various difficulties. Probably the most serious one appears after the depletion depth has reached the radius of spheres or necks. Such situation can happen easily when the size of spheres is reduced or gas adsorption is strengthened. Both models hardly seem to be applicable to such a situation. In our opinion, (b) seems to survive in various situations. Actually theoretical treatises in this article are based on this model.

It is remarked that important information concerning the transducer function is available from the Hall effects measurement. As generally accepted, conductance, $\sigma$, for an $\mathrm{n}$-type semiconductor is given by the density, $[e]$, and mobility, $\mu$, of charge carriers (electrons) as follows:

$$
\sigma=-q[e] \mu \text {. }
$$

Here $q$ is the electric charge of proton. The values of $[e]$ and $\mu$ can be estimated independently from the Hall effects measurement. The measurements on semiconductor gas sensor devices have been carried out by Japanese experts [29, $30]$. According to their results, $\sigma$ and $[e]$ changed in parallel to each other with increasing concentration of reducing gases while $\mu$ was kept almost constant, as measured for sputtered $\mathrm{SnO}_{2}$ thick film devices. This means that the change of $[e]$ is responsible exclusively for the change of $\sigma$, thus supporting the tunneling transport model (b) in Figure 10. 


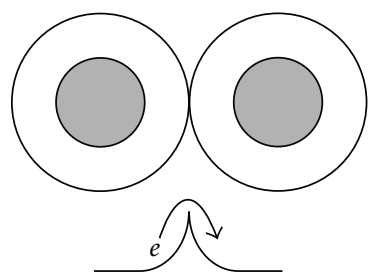

(a)

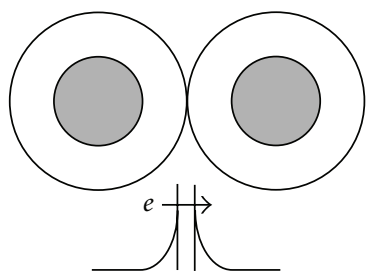

(b)

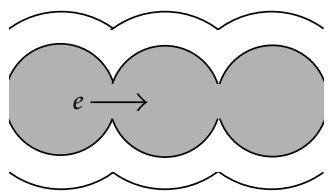

(c)

Figure 10: Models for electron transport between adjacent crystals.

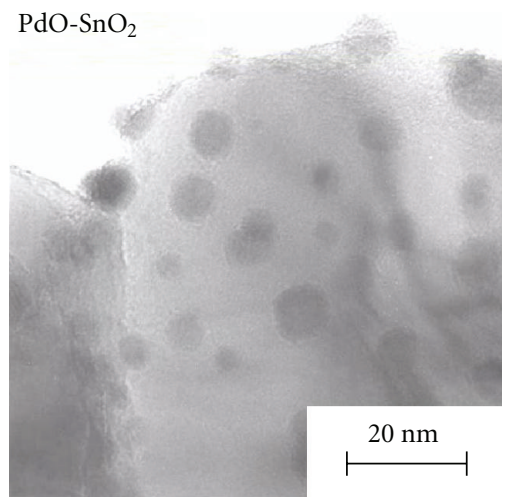

Figure 11: State of deposits of $\mathrm{PdO}$ on $\mathrm{SnO}_{2}$ grain as observed on TEM [31].

An exceptional case has been reported with an $\mathrm{SnO}_{2}$ device fabricated from tin metal by an evaporation and oxidation method [29]. In this case, both [e] and $\mu$ increased with increasing concentration of target gas (ethanol), resulting in enhanced sensitivity of $\sigma$ as compared with the sputtered devices. This difference in the behavior of $\mu$ probably arose from a change in the morphology of the constituent crystals. The authors explained such gas sensitivity of $\mu$ as resulting from very small crystals on the basis of a neck model like one shown as (c) in Figure 10, but it seems difficult to explain the gas sensitivity of $[e]$ based on this model. The tunneling transport model, on the other hand, seems to account for the sensitivity of both $[e]$ and $\mu$ better provided that dispersion in crystal size is admitted, though this is yet to be done.

2.5. Sensitization by Foreign Substances. As mentioned in Section 1, actual sensor devices are almost always loaded with small amounts of foreign substances so called sensitizers. Kinds of sensitizers used or confirmed are quite various, including noble metals ( $\mathrm{Pt}$ and $\mathrm{Au}$ ), noble metal oxides (PdO, $\mathrm{Ag}_{2} \mathrm{O}, \mathrm{Rh}_{2} \mathrm{O}_{3}$, etc.), base metal oxides $\left(\mathrm{Fe}_{2} \mathrm{O}_{3}, \mathrm{Co}_{3} \mathrm{O}_{4}\right.$, etc.), alkaline or rare earth metal oxides $\left(\mathrm{CaO}, \mathrm{La}_{2} \mathrm{O}_{3}\right.$, etc.), and alkali metal oxide $\left(\mathrm{Rb}_{2} \mathrm{O}\right)$. To make sensitization in effect, sensitizers should be dispersed well on the constituent crystals of the sensor devices. As shown in Figure 11 [31], sensitizers are usually deposited as small particles adhering well to the underlying crystals. However, the roles of sensitizers (sensitization mechanisms) have not always been made clear. Beside the sensitization through modifying the acid-base property of the crystal surface which is vitally important in acid-base catalyzed reactions like the oxidation of alcohols, we have proposed two types of sensitization mechanisms, that is, chemical sensitization and electronic sensitization, operative for reducing gases [32]. The chemical sensitization is brought about from the catalytic actions of sensitizers like Pt. When target gas is resistant to oxidation like methane, for example, it is activated (or transformed) into more reactive intermediates like aldehydes before being exposed to the crystal surface. The electronic sensitization is in effect when the foreign substances draw electrons from the crystals, as easily witnessed from an increase in device resistance. Many of the sensitizers known are p-type oxides so that formation of $\mathrm{p}-\mathrm{n}$ junctions between the tiny deposits of sensitizers and underlying $\mathrm{SnO}_{2}$ (n-type) does not seem to be so unlikely. It has been shown that work function of $\mathrm{SnO}_{2}$ is increased significantly by the loading with $\mathrm{PdO}$ (about $0.1 \mathrm{eV}), \mathrm{Ag}_{2} \mathrm{O}(0.3 \mathrm{eV})$ and $\mathrm{CuO}(0.5 \mathrm{eV})$, as measured on XPS [33]. Here the figures in the parentheses are increments of work function in respective cases. In these cases, each sensitizer can undergo a redox change and, when it is reduced with the target gases, work function and device resistance have been confirmed to go back to their original values. It has been thus inferred that coupling of the formation of $\mathrm{p}-\mathrm{n}$ junctions and the redox changes results in the sensitization. This mechanism, however, encounters difficulties in accounting for the sensitization exerted by the other sensitizers like $\mathrm{Au}, \mathrm{Fe}_{2} \mathrm{O}_{3}, \mathrm{Co}_{3} \mathrm{O}_{4}$, and $\mathrm{Rb}_{2} \mathrm{O}$, which increase work function of $\mathrm{SnO}_{2}$ more or less but are less facile or totally stable to redox changes. It seems that there are different mechanisms of electronic sensitization which cover the redox changes-free cases. Theoretical approaches to this issue are worth being carried out.

\section{Theoretical Approach to Sensor Response to Oxygen}

For a long time, the mechanism of gas sensing has been one of the most interested subjects in semiconductor gas sensors. Despite many efforts so far made, however, few have succeeded in revealing it from a fundamental point of view. As known well, chemisorption and catalysis of gas molecules on semiconductor surfaces were paid much attention in the age earlier than the inauguration of semiconductor gas sensors. An electronic theory was proposed to explain chemisorption and catalysis on semiconductors [34-36]. It explains well how the electron transfer between adsobates and semiconductor results in the formation of a depletion, accumulation, or inversion layer in the subsurface of semiconductors. When applied for semiconductor gas sensors, it has been useful in understanding their behavior qualitatively. Unfortunately, however, no quantitative understandings have been available with it. There are several reasons for this, and the most serious one is, in our opinion, that the theory cannot deal 


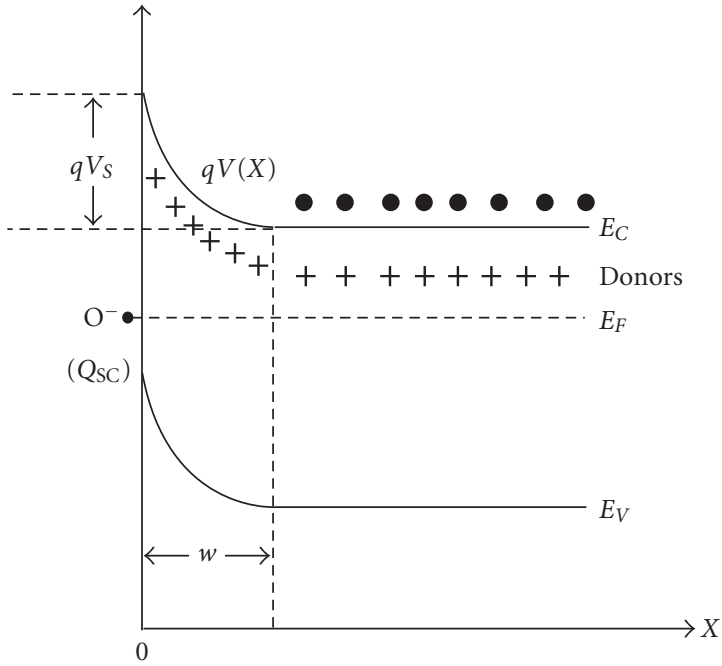

FIGURE 12: Schematic diagram of electrostatic equilibrium for large semiconductor crystals under exposure to oxygen. Ec: conduction band edge, Ec: valence band edge, $\mathrm{E}_{F}$ : Fermi level, $Q_{\mathrm{sc}}$ : surface charge density, $w$ : depletion depth, $q V$ : potential energy of electrons, $q V_{s}$ : surface potential energy barrier [37].

correctly with so small semiconductor crystals as used in gas sensors. As easily understood, response to oxygen is a starting base of semiconductor gas sensors. The sensors are active in air, being alert to the access of target gases. In the beginning of this section, this theory is applied to the response to oxygen to demonstrate what comes out. Then a new theory is introduced to deal with small crystals, which is indispensable for understanding the response behavior of semiconductor gas sensors. In the following treatments, the semiconductor crystals taken into consideration are shaped in plate unless otherwise noted, because mathematical expressions for other shapes, sphere and column, become far more complex and tedious due to shape effect.

3.1. Conventional Theory of Depletion (Large Crystals). Depletion of large semiconductor crystals can be treated with the conventional theory. Let us consider the adsorption of electron-accepting molecules (typically $\mathrm{O}_{2}$ ) on the surface of a large n-type semiconductor crystal. This situation is well approximated by the adsorption on a plane of a large crystal cleaved in halves, as schematically drawn in Figure 12 [37]. As a result of electron transfer, a depletion layer is formed in the subsurface region, the layer thickness increasing with an increase in electron transfer. The electron transfer reaches equilibrium when Fermi level at the adsorbed species coincides with that in the semiconductor bulk.

The electrostatic equilibrium inside the crystal in such a case can be treated quantitatively under simplifying assumptions. Conventionally it is assumed that (1) donors are ionized completely, (2) there are no other electron-traps other than the adsorbates, and (3) all of conduction electrons up to a depth $\mathrm{w}$ are completely transferred to the surface (abrupt model). Since donors in $\mathrm{SnO}_{2}$ are reportedly present at shallow levels $(0.05-0.15 \mathrm{eV})$ below the conduction band edge [38], the first assumption can be acceptable fairly well. The second one may be fit to an ionic semiconductor like $\mathrm{SnO}_{2}$ better than to a nonionic semiconductor like silicon. The third one, though useful in simplifying mathematical treatments, cannot always be rationalized as mentioned later. However, abrupt model is used here always unless otherwise noted.

Under these assumptions, the density of surface charges, $Q_{\text {SC }}$, is nominally equal to $-q N_{d} w$, where $q$ is electric charge of proton and $N_{d}$ the density of donors of semiconductor:

$$
Q_{\mathrm{SC}}=-q N_{d} w=-q N_{d} L_{D} m .
$$

Here $m$ is reduced depletion depth defined by $m=w / L_{D}$. Under these conditions, electric potential, $V$, in the depletion region should satisfy the following Poisson's equation, where $x$ is the depth from the surface and $\varepsilon$ is the permittivity of semiconductor times the free space permittivity:

$$
\frac{d^{2} V}{d x^{2}}=-\frac{q N_{d}}{\varepsilon} .
$$

By introducing the boundary conditions that $d V / d x$ as well as $V$ are zero at $x=w,(3)$ is solved to give the following depth profile of electric potential:

$$
V(x)=-\left(\frac{q N_{d}}{2 \varepsilon}\right)(x-w)^{2} .
$$

Potential energy of electrons, $q V(x)$, as well as the height of surface potential barrier, $q V_{S}$, are obtained from (4):

$$
\begin{aligned}
& \frac{q V(x)}{k T}=\left(\frac{q^{2} N_{d}}{2 \varepsilon k T}\right)(x-w)^{2} \\
&=\left(\frac{1}{2}\right)\left\{\frac{(x-w)}{L_{D}}\right\}^{2}, \\
& \frac{q V(X)}{k T}=\left(\frac{1}{2}\right)(X-m)^{2}, \\
& \frac{q V S}{k T}=\left(\frac{1}{2}\right)\left(\frac{w}{L_{D}}\right)^{2}=\left(\frac{1}{2}\right) m^{2} .
\end{aligned}
$$

Here $L_{D}$ is the Debye length of semiconductor given by $L_{D}=$ $\left(q^{2} N_{d} / k T\right)^{-1 / 2}$, and $X$ is reduced distance defined by $X=$ $x / L_{D}$. The density of electrons at the surface, $[e]_{S}$, is given from (6) as follows:

$$
[e]_{S}=N_{d} \exp \left(\frac{-q V S}{k T}\right)=N_{d} \exp \left(\frac{-m^{2}}{2}\right) .
$$

In this way, the surface density of adsorbates, $-Q_{\mathrm{SC}} / q$, and electrons can be correlated uniquely through m once $L_{D}$ and $N_{d}$ are given.

3.2. Response of Large Crystals. It is assumed that oxygen is adsorbed as $\mathrm{O}^{-}$exclusively on the semiconductor surface. Then the overall equation of oxygen adsorption and its equilibrium are expressed as follows:

$$
\begin{gathered}
\mathrm{O}_{2}+2 e=2 \mathrm{O}^{-}, \\
\left(K_{\mathrm{O}_{2}} P_{\mathrm{O}_{2}}\right)^{1 / 2}[e]_{S}=\left[\mathrm{O}^{-}\right] .
\end{gathered}
$$




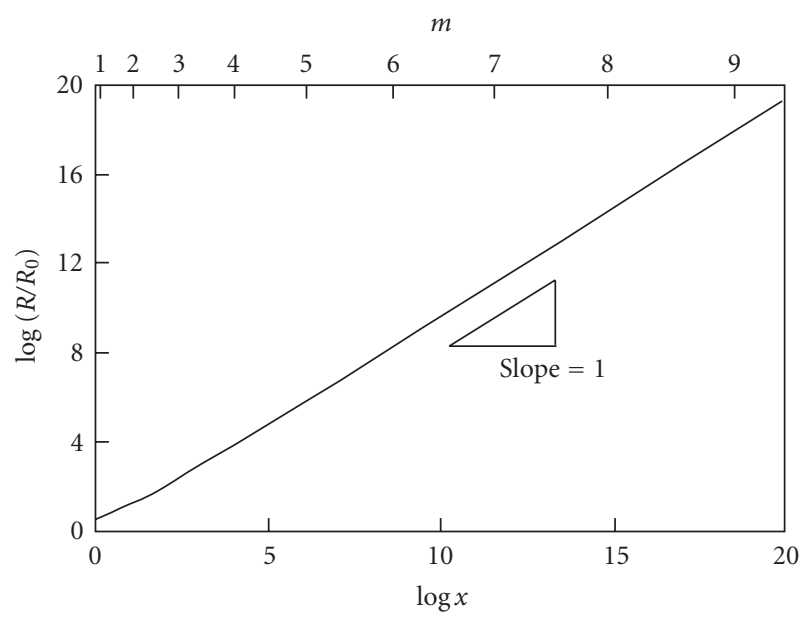

Figure 13: Correlation between $R / R_{0}$ and $X$ on logarithmic scales [14]. $X=\left(K_{\mathrm{O}_{2}} P_{\mathrm{O}_{2}}\right)^{1 / 2} / L_{D}$

$K_{\mathrm{O}_{2}}$ and $P_{\mathrm{O}_{2}}$ are the adsorption constant and the partial pressure of oxygen, respectively, and $[e]_{S}$ and $\left[\mathrm{O}^{-}\right]$are the surface densities of free electrons and $\mathrm{O}^{-}$, respectively. Equation (8) indicates that $\left(K_{\mathrm{O}_{2}} P_{\mathrm{O}_{2}}\right)^{1 / 2}$ determines the density ratio, $\left[\mathrm{O}^{-}\right] /[e]_{S}$, not the respective quantities. These quantities are determined only after the chemical equilibrium is coupled with the electrostatic equilibrium just mentioned.

When $\mathrm{O}^{-}$is solely responsible for the total charge density of the semiconductor as assumed,

$$
\left[\mathrm{O}^{-}\right]=\frac{-Q_{S C}}{q}=N_{d} L_{D} m .
$$

By inserting (2) and (8) into (7), we obtain

$$
\begin{gathered}
\left(K_{\mathrm{O}_{2}} P_{\mathrm{O}_{2}}\right)^{1 / 2} N_{d} \exp \left(\frac{-m^{2}}{2}\right)=N_{d} L_{D} m, \\
X=m \exp \left(\frac{m^{2}}{2}\right) .
\end{gathered}
$$

Here $X$ is reduced adsorption strength of oxygen defined by $X=\left(K_{\mathrm{O}_{2}} P_{\mathrm{O}_{2}}\right)^{1 / 2} / L_{D}$. Indication of $(10)$ is that if $X$ is given, $m$ is determined uniquely. This in turn determines $[e]_{S}$ through (8). Thus we can correlate oxygen adsorption with the surface density of electrons.

In order to obtain the correlation with sensor resistance $(R)$, we need to know the relation between $R$ and $[e]_{S}$. The relation is simple if the tunneling transport model (Figure 10(b)) is assumed, as follows:

$$
\frac{R}{R_{0}}=\frac{[e]_{S 0}}{[e]_{S}}=\exp \left(\frac{m^{2}}{2}\right)
$$

Here $R_{0}$ and $[e]_{S 0}$ are the values of $R$ and $[e]_{S}$ at the flat band state, respectively. The latter quantity coincides with $N_{d}$ for the simplified mode used here. $R$ and $R_{0}$ are influenced by many factors other than oxygen adsorption, such as packing of crystals and geometry of sensor device, but those influences can be canceled out effectively by normalizing $R$

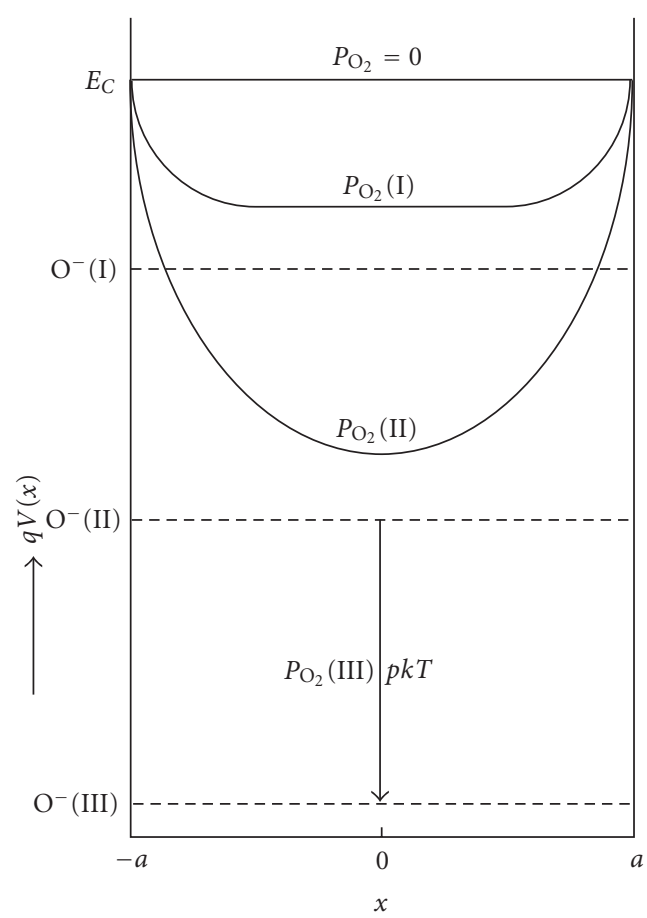

(a)

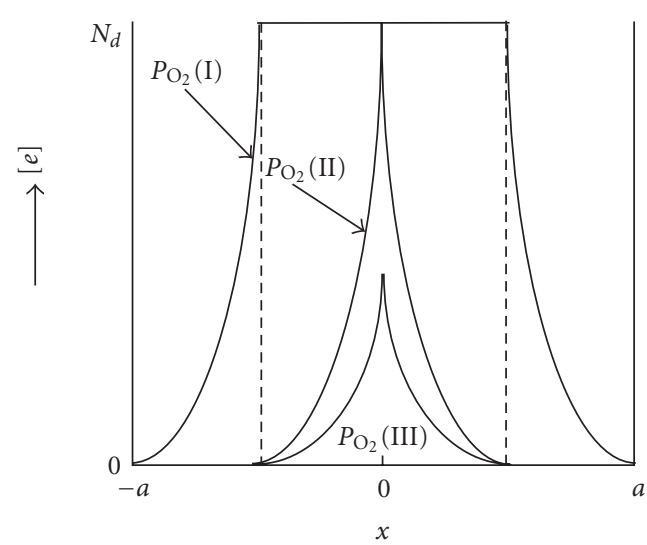

(b)

Figure 14: Schematic diagrams of electronic equilibrium for semiconductor plate (half thickness $a$ ) placed under various partial pressures of oxygen $\left(P_{\mathrm{O}_{2}}\right)$. (a) Depth profiles of potential energy. (b) Depth profiles of conduction electrons density assumed on abrupt model (broken lines) and modified model (full lines). See section 3.6 for modified model [15].

by $R_{0}$. The correlation between $R / R_{0}$ and $X$ thus obtained through (10) and (11) is shown on logarithmic scales in Figure 13 [14]. $R / R_{0}$ increases with increasing $X$ and its slope becomes equal to unity in the middle region of $X$, explaining that the power law-type dependence of $R$ on $P_{\mathrm{O}_{2}}$ with a power index of $1 / 2$ is actually observed. However, no important information else can be obtained from such a treatise. Similar conclusions have been obtained for the responses to $\mathrm{NO}_{2}$ and $\mathrm{H}_{2}$ [14]. This is because we have used conventional theory of depletion developed for large crystals, thus missing important information about the size and shape of crystals. 
3.3. Two Types of Depletion in Small Crystals. Let us consider how depletion develops in a plate crystal of thickness $2 a$ (a, half thickness), starting from the flat-band state, with increasing $P_{\mathrm{O}_{2}}$ in the ambient. The electrostatic equilibrium of this system is schematically drawn in Figure 14(a). When $P_{\mathrm{O}_{2}}$ is small, depletion takes place in the same way as previously seen in a large crystal, depletion depth increasing with increasing $P_{\mathrm{O}_{2}}$. However, this way of depletion is finished at $P_{\mathrm{O}_{2}}$ (II) where depletion has extended to cover the whole region of the crystal. Obviously the value of $P_{\mathrm{O}_{2}}$ (II) decreases with decreasing half thickness $(a)$. What would happen when $P_{\mathrm{O}_{2}}$ is further increased to $P_{\mathrm{O}_{2}}(\mathrm{III})$ ) in the figure? This is a main concern here. The above limit of depletion comes solely from the physics of the crystal. The chemistry of oxygen adsorption, on the other hand, does not care the physics. It requires (8) to hold at any stages, or, speaking more specifically, the ratio $\left[\mathrm{O}^{-}\right] /[e]_{S}$ to increase linearly with increasing $X=\left(K_{\mathrm{O}_{2}} P_{\mathrm{O}_{2}}\right)^{1 / 2}$. In order for the physics side (electrostatic equilibrium) to fulfill this requirement, the only available way is to allow Fermi level to shift down by a designated amount, $p k T$, whereas the band bending profile is kept unchanged. With this shift, not only the whole region from the surface adsorbates $\left(\mathrm{O}^{-}\right)$to the bulk of the crystal can be placed at the same Fermi level but also the potential energy of electrons goes up to the level at which $[e]_{S}$ takes a value consistent with the chemical equilibrium condition (8). This way of establishing the electrostatic equilibrium is thus very different from one observed at lower $P_{\mathrm{O}_{2}}$. It is noted that electron transfer from the bulk to the surface continues still in this stage, though it is only nominal when the abrupt model is used (Figure 14(b)). The electron transfer is made more apparent in case some electrons are left behind in the depletion layer (modified model) as illustrated in the same figure. In this case, the density of electrons inside the crystal decreases progressively as the Fermi level shift increases, showing that electrons are squeezed out from the whole crystal to be supplied to the surface. It is therefore convenient to distinguish the depletion in this stage from the conventional one in the initial stage up to $P_{\mathrm{O}_{2}}$ (II). We call them here volume depletion and regional depletion, respectively, while the border in between is called boundary depletion.

3.4. Response at Regional Depletion (Plate). As mentioned earlier, the occurrence of regional depletion followed by volume depletion is characteristic to small crystals. Receptor function and response of small plate crystals to oxygen in the stage of regional depletion are discussed here. The distribution of potential inside the plate is obtained by solving Poisson's equation, which is the same as (3) but has an origin located at a center of the plate with coordinate $x$ being taken as a distance normal to the surface from origin (see Figure 14). In the stage of regional depletion, potential energy of electrons is expressed as shown below:

$$
\begin{aligned}
q V(x) & =\left(\frac{q^{2} N_{d}}{2 \varepsilon}\right)\{x-(a-w)\}^{2} & & \text { for }|x| \geqq a-w, \\
& =0 & & \text { for }|x|<a-w .
\end{aligned}
$$

These are rewritten in reduced form as

$$
\begin{aligned}
\frac{q V(X)}{k T} & =\left(\frac{1}{2}\right)\{X-(n-m)\}^{2} & & \text { for }|x| \geqq n-m, \\
& =0 & & \text { for }|x|<n-m .
\end{aligned}
$$

Reduced quantities, $X$ and $m$, are the same as defined before, and $n$ is reduced size defined by $n=a / L_{D}$. These expressions are essentially the same as those derived for large crystals, though depletion in this case starts from both surfaces. Surface potential energy (barrier) is expressed by the same equation (7), while (9) holds also as assumed. As a result, either of (10) and (11) derived for large crystals can be used to correlate between $R / R_{0}$ and $X$ also in this case. It is noted, however, that this can be valid only for plate crystals, which are free from the shape effect.

3.5. Response at Volume Depletion (Plate). Potential energy in the stage of boundary depletion is obtained by inserting $w=a$ in (12) or $m=n$ in (13) and that in volume depletion is larger by $p k T$ or $p$, as follows:

$$
\begin{gathered}
q V(x)=\left(\frac{q^{2} N_{d}}{2 \varepsilon}\right) x^{2}+p k T . \\
\frac{q V(X)}{k T}=\left(\frac{1}{2}\right) X^{2}+p .
\end{gathered}
$$

Here $p=0$ indicates boundary depletion. The surface potential energy is obtained by inserting $X=n$ into (15):

$$
\frac{q V_{s}}{k T}=\left(\frac{1}{2}\right) n^{2}+p
$$

We can then express $[e]_{S}$ and $R / R_{0}$ by using $n$ and $p \cdot\left[\mathrm{O}^{-}\right]$ is obtained from (9) if $m$ is replaced by $n$. By inserting these quantities into the mass action law (8), we can correlate $X$ with $n$ and $p$. Thus we obtain a couple of equations:

$$
\begin{aligned}
& X=n \exp \left\{\left(\frac{1}{2}\right) n^{2}+p\right\}, \\
& \frac{R}{R_{0}}=\exp \left\{\left(\frac{1}{2}\right) n^{2}+p\right\} .
\end{aligned}
$$

These equations determine the correlation between $R / R_{0}$ and $X$. Unlike the case of regional depletion, however, $R / R_{0}$ is an explicit function of $X$, because we obtain from the couple of equations

$$
\frac{R}{R_{0}}=\frac{X}{n}=\frac{\left(K_{\mathrm{O}_{2}} P_{\mathrm{O}_{2}}\right)^{1 / 2}}{a} .
$$

Normalized resistance is thus linear to $\left(K_{\mathrm{O}_{2}} P_{\mathrm{O}_{2}}\right)^{1 / 2}$ and the reciprocal of $a$.

The correlations between $R / R_{0}$ and $X$ in the stages of regional depletion and volume depletion are drawn for smaller selected values of $n$ in Figure 15. In principle, regional depletion always precedes another on increasing $X$, but actually when $n$ is small it is not visible well in the drawing on this scale, allowing volume depletion to prevail. 
It is also clear that the slope of each correlation (sensitivity to oxygen) increases sharply with decreasing $n$ and is inversely proportional to $n$ or $a$ in the stage of volume depletion. This indicates a size effect on the sensor response to oxygen. It is remarked that the derivative of $R$ or normalized $R$ with respect to the concentration (or partial pressure) of target gas in problem is usually defined as sensor sensitivity. In the case of oxygen adsorption, however, the sensitivity is better defined as the derivative of $R / R_{0}$ with respect to $P_{\mathrm{O}_{2}}{ }^{1 / 2}$, which is equal to $K_{\mathrm{O}_{2}}{ }^{1 / 2} / a$ in the stage of volume depletion.

3.6. Effects of Shape and Size. The same treatment can be extended to spherical crystals (radius $a$ ) and columnar crystals (columnar radius a). For this purpose, two things should be taken into account. First, Poisson's equation is transformed, for the convenience of solution, into one fitting to the symmetry of the crystal form. A polar spherical coordinates system and a columnar coordinates system are illustrated together with one-dimensional system so far used in Figure 16. In the respective systems, Poisson's equation is expressed as a function of a single variable as follows:

$$
\begin{gathered}
\frac{d^{2} V}{d x^{2}}=\frac{-q N_{d}}{\varepsilon}, \quad \text { (Plate), } \\
\left(\frac{1}{r^{2}}\right) \frac{d}{d r}\left(\frac{r^{2} d V}{d r}\right)=\frac{-q N_{d}}{\varepsilon}, \quad \text { (Sphere), } \\
\left(\frac{1}{r}\right) \frac{d}{d r}\left(\frac{r d V}{d r}\right)=\frac{-q N_{d}}{\varepsilon}, \quad \text { (Column). }
\end{gathered}
$$

Here $r$ is radial displacement from the center of crystals. Each equation can be solved by using the same boundary conditions as used before to give a solution shown below:

$$
\begin{gathered}
V(x)=-\left(\frac{q N_{d}}{2 \varepsilon}\right)\{x-(a-w)\}^{2}, \quad \text { (Plate), } \\
V(r)=-\frac{\left(q N_{d} / 2 \varepsilon\right)\{r-(a-w)\}^{2}\{1+2(a-w) / r\}}{3}, \\
V(r)=-\left(\frac{q N_{d}}{4 \varepsilon}\right)\left\{r^{2}-(a-w)^{2}\left[1+2 \ln \left(\frac{r}{(a--w)}\right)\right]\right\},
\end{gathered}
$$

(Column).

Second, the relations between total surface charge density $\left(Q_{\mathrm{SC}}\right)$ and depletion depth $(w$ or $m)$ should be altered to meet crystal symmetry:

$$
\begin{aligned}
\frac{Q_{\mathrm{SC}}}{q} & =-N_{d} w=-N_{d} L_{D} m, \quad(\text { Plate }), \\
\frac{Q_{\mathrm{SC}}}{q} & =\frac{-N_{d}\left\{\int_{a-w}^{a} 4 \pi r^{2} d r\right\}}{\left(4 \pi a^{2}\right)} \\
& =-\left(\frac{1}{3}\right) N_{d} L_{D} n\left\{1-\left[\frac{(n-m)}{n}\right]^{3}\right\}, \quad \text { (Sphere) }
\end{aligned}
$$

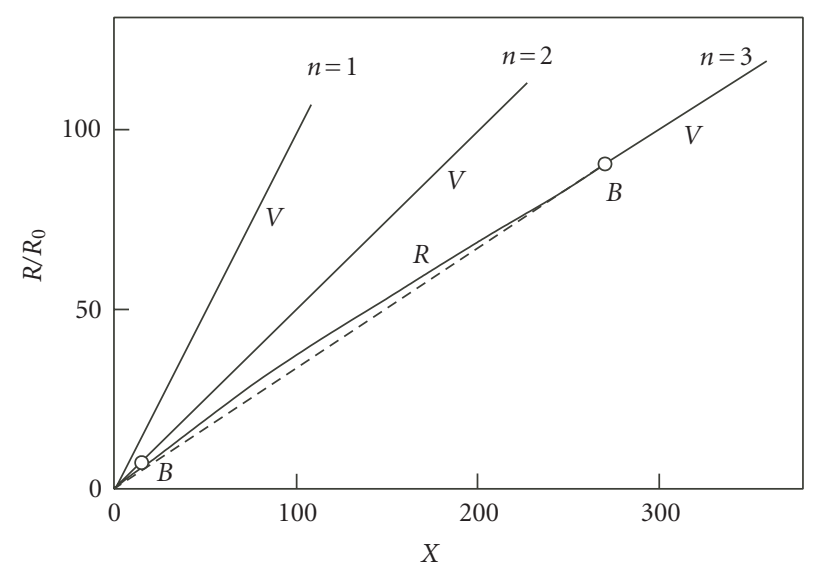

Figure 15: Correlations between $R / R_{0}$ and $X$ for plate crystals with reduced thickness $n$ [17].

$$
\begin{aligned}
\frac{Q_{\mathrm{SC}}}{q} & =-N_{d} \frac{\left\{\int_{a-w}^{a} 2 \pi r d r\right\}}{(2 \pi a)} \\
& =-\left(\frac{1}{2}\right) N_{d} L_{D} n\left\{1-\left[\frac{(n-m)}{n}\right]^{2}\right\}, \quad \text { (Column). }
\end{aligned}
$$

Here $m$ and $n$ are reduced depletion depth $\left(w / L_{D}\right)$ and reduced size $\left(a / L_{D}\right)$, respectively.

Based on the abrupt model, receptor function and sensor response to oxygen can be formulated for spherical and columnar crystals in the same way as done for plate crystals. The correlations between $R / R_{0}$ and $X$ thus derived are summarized as follows.

Regional depletion. Plate:

$$
\begin{aligned}
& X=m \exp \left(\frac{m^{2}}{2}\right), \\
& \frac{R}{R_{0}}=\exp \left(\frac{m^{2}}{2}\right) ;
\end{aligned}
$$

Sphere:

$$
\begin{aligned}
X= & \left(\frac{n}{3}\right)\left\{1-\left[\frac{(n-m)}{n}\right]^{3}\right\} \\
& \times \exp \left\{\left(\frac{m^{2}}{6}\right)\left[1+2 \frac{(n-m)}{n}\right]\right\}, \\
\frac{R}{R_{0}}= & \exp \left(\frac{m^{2}}{6}\right)\left\{\left[1+2 \frac{(n-m)}{n}\right]\right\} ;
\end{aligned}
$$


Column:

$$
\begin{aligned}
X= & \left(\frac{n}{2}\right)\left\{1-\left[\frac{(n-m)}{n}\right]^{2}\right\} \\
& \times \exp \left\{\left(\frac{1}{4}\right)\left[n^{2}-(n-m)^{2}\left[1+2 \ln \left(\frac{n}{(n-m)}\right)\right]\right]\right\}, \\
\frac{R}{R_{0}}= & \exp \left\{\left(\frac{1}{4}\right)\left[n^{2}-(n-m)^{2}\left[1+2 \ln \left(\frac{n}{(n-m)}\right)\right]\right]\right\} .
\end{aligned}
$$

Volume depletion.

$$
\frac{R}{R_{0}}=\left(\frac{S}{a}\right)\left(K_{\mathrm{O}_{2}} P_{\mathrm{O}_{2}}\right)^{1 / 2},
$$

$S=1$ (plate), 2 (column), or 3 (sphere).

$S$ is the shape factor, which coincides with the surface area to volume ratio for each crystal shape. In the stage of volume depletion, sensitivity to oxygen decreases in the order, sphere $>$ column $>$ plate, due to the shape factor when $a$ is the same.

It would be instructive to estimate roughly the values of $L_{D}$ and $n$ for $\mathrm{SnO}_{2}$ crystals. Martinelli et al. have reported that the permittivity and the donor density of $\mathrm{SnO}_{2}$ are $10^{-10} \mathrm{Fm}^{-1}$ and $4.1 \times 10^{18} \mathrm{~cm}^{-3}$, respectively, [39]. These values allow us to estimate $L_{D}=2.8 \mathrm{~nm}$ at $600 \mathrm{~K}$. Actually, however, donor density values are scattered rather largely depending on reports and the highest one is $1.5 \times 10^{19} \mathrm{~cm}^{-3}$ [27], which leads to $L_{D}=1.4 \mathrm{~nm}$. When we assume the former $L_{D}$ value, $\mathrm{SnO}_{2}$ grains of about $20 \mathrm{~nm}$ in diameter usually adapted in actual devices have $n=3.6$. Then regional depletion in these grains is finished at the reduced depletion depth $m=n=3.6$, which leads to $R / R_{0}=8.7, X=10.4$, and $K_{\mathrm{O}_{2}} P_{\mathrm{O}_{2}}=1.5 \times 10^{3} \mathrm{~nm}^{2} \mathrm{~atm}^{-1}$ according to (23). It follows that this value of $R / R_{0}$ is the maximum response to oxygen allowed by regional depletion, and therefore the maximum of conventional sensor response to reducing gases in air $\left(R_{a} / R_{g}\right)$ as well. It is understood that larger responses in $R / R_{0}$ and $R_{a} / R_{g}$ can never be acquired without the help of volume depletion.

3.7. Corrections for the Tailing of Electron Distribution. The abrupt model used above cannot always be rationalized, as mentioned. The assumption of complete transfer of electrons from the depletion region to the surface can be too drastic. It is likely that some electrons are left behind in the vicinity of the depletion frontier where potential energy of electrons remains modest, resulting in a tailing of electron distribution. For usual semiconductor devices, a distribution tail due to thermal fluctuations of electrons has been taken into consideration for correction [37]. However, this correction having aimed at applications for thick semiconductor devices hardly seems to be effective in gas sensors. It is worth remembering that the electron concentration at the surface, $[e]_{S}$, is estimated from $V_{S}$ by assuming the Boltzmann distribution law. Then it would not be so unreasonable to assume that the same distribution law operates over the whole depletion region. If this assumption is admitted, the amount of electrons transferred from the bulk to the surface, which contributes to $-Q_{\mathrm{sC}} / q$, can be estimated exactly from the potential energy profiles as follows:

$$
\begin{aligned}
& \frac{-Q_{\mathrm{SC}}}{q}=N_{d} \int_{a-w}^{a}\left\{1-\exp \left(-\frac{q V(x)}{k T}\right)\right\} d x, \quad \text { (Plate), } \\
& \frac{-4 \pi a^{2} Q_{\mathrm{SC}}}{q}=N_{d} \int_{a-w}^{a}\left\{1-\exp \left(-\frac{q V(r)}{k T}\right)\right\} 4 \pi r^{2} d r, \\
& \text { (Sphere), } \\
& \frac{-2 \pi a Q_{\mathrm{SC}}}{q}=N_{d} \int_{a-w}^{a}\left\{1-\exp \left(-\frac{q V(r)}{k T}\right)\right\} 2 \pi r d r,
\end{aligned}
$$

(Column).

Rearrangements result in

$$
\begin{aligned}
\frac{-Q_{\mathrm{SC}}}{q N_{d} L_{D}}= & m-\int_{n-m}^{n} \exp \left(-\frac{q V(x)}{k T}\right) d X, \quad \text { (Plate), } \\
\frac{-Q_{\mathrm{SC}}}{q N_{d} L_{D}}= & \left(\frac{n}{3}\right)\left\{1-\left[\frac{(n-m)}{n}\right]^{3}\right\} \\
& -\left(\frac{1}{n^{2}}\right) \int_{n-m}^{n} R^{2} \exp \left(-\frac{q V(R)}{k T}\right) d R, \quad \text { (Sphere), } \\
\frac{-Q_{\mathrm{SC}}}{q N_{d} L_{D}}= & \left(\frac{n}{2}\right)\left\{1-\left[\frac{(n-m)}{n}\right]^{2}\right\} \\
& -\left(\frac{1}{n}\right) \int_{n-m}^{n} R \exp \left(-\frac{q V(R)}{k T}\right) d R, \quad \text { (Column). }
\end{aligned}
$$

The second term in each equation represents the quantity to be corrected for the tailing effect. Once such a correction is available, the correlations between $R / R_{0}$ and $X$ can be formulated in the same way as done before. The results are summarized below.

Regional depletion. Plate:

$$
\begin{gathered}
X=\left(m-A_{P}(m)\right) \exp \left(\frac{m^{2}}{2}\right), \\
\frac{R}{R_{0}}=\exp \left(\frac{m^{2}}{2}\right) ;
\end{gathered}
$$

Sphere:

$$
\begin{gathered}
X=\left\{\left(\frac{n}{3}\right)\left\{1-\left[\frac{(n-m)}{n}\right]^{3}\right\}-A_{S}(n, m)\right\} \\
\times \exp \left\{\left(\frac{m^{2}}{6}\right)\left[1+2 \frac{(n-m)}{n}\right]\right\}, \\
\frac{R}{R_{0}}=\exp \left\{\left(\frac{m^{2}}{6}\right)\left[1+2 \frac{(n-m)}{n}\right]\right\} ;
\end{gathered}
$$




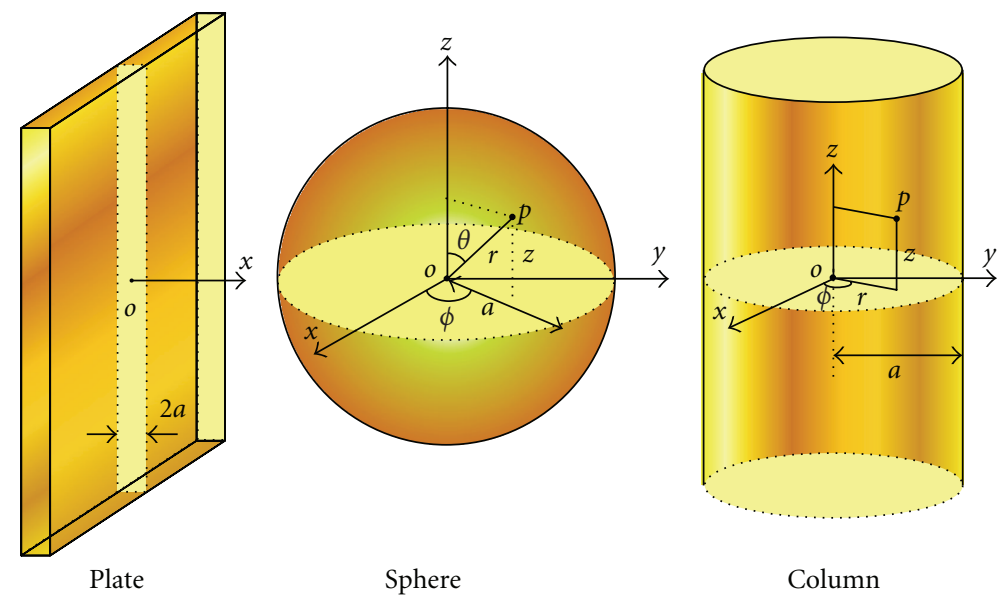

FIgURE 16: Coordinates systems adapted for plate, sphere, and column [15].

Column:

$$
\begin{aligned}
X= & \left\{\left(\frac{n}{2}\right)\left\{1-\left[\frac{(n-m)}{n}\right]^{2}\right\}-A_{C}(n, m)\right\} \\
& \times \exp \left\{\left(\frac{1}{4}\right)\left[n^{2}-(n-m)^{2}\left[1+2 \ln \left(\frac{n}{(n-m)}\right)\right]\right],\right. \\
\frac{R}{R_{0}}= & \exp \left\{\left(\frac{1}{4}\right)\left[n^{2}-(n-m)^{2}\left[1+2 \ln \left(\frac{n}{(n-m)}\right)\right]\right]\right\} .
\end{aligned}
$$

$A(m)$ or $A(n, m)$ is the correction term appearing in (27) through (29), and suffices, $P, S$, and $C$ standing for plate, sphere, and column.

Volum depletion. Plate:

$$
\frac{R}{R_{0}}=\left(\frac{1}{n}\right) X+\left(\frac{1}{n}\right) A_{P}(n) \exp \left(\frac{n^{2}}{2}\right)
$$

Sphere:

$$
\frac{R}{R_{0}}=\left(\frac{3}{n}\right) X+\left(\frac{3}{n}\right) A_{S}(n) \exp \left(\frac{n^{2}}{6}\right)
$$

Column:

$$
\frac{R}{R_{0}}=\left(\frac{2}{n}\right) X+\left(\frac{2}{n}\right) A_{C}(n) \exp \left(\frac{n^{2}}{4}\right) .
$$

$A(n)$ is the value of $A(m)$ or $A(n, m)$ at the boundary depletion $(m=n)$. In each equation, the second term (intercept) is close to unity for smaller values of $n$ but it increases rather sharply with increasing $n$ in a range of larger $n$.

The correlations given by these equations are shown for the cases of planar and spherical crystals in (a) and (b) in Figure 17, respectively. Compared with Figure 15, the correlations for plate crystals (a) are more convex upward in the stage of regional depletion and this tendency becomes more conspicuous as $\mathrm{n}$ increases. Those for volume depletion, on the other hand, are straight lines, which now have intercepts against ordinate. Such behavior of the correlations seems to fit better to actual observations. However, the assumption used for the correction needs to be checked thoroughly for verification.

3.8. Comparison with Experiments. Although the measurement of device resistance as a function of $\mathrm{P}_{\mathrm{O} 2}$ is a very basic task, carrying out it satisfactorily has turned out to be surprisingly difficult. The resistance is sensitive to trace amounts of surface-active impurities, that is, contaminant reducing gases at ppm or sub-ppm levels in commercial tubes of oxygen or of oxygen diluted with nitrogen, and contaminant oxygen as well as contaminant reducing gases in high purity nitrogen. Since these tube gases are mixed together to control $P_{\mathrm{O}_{2}}$, contaminants can be serious origins of disturbances. It is necessary to reduce contaminants as much as possible but complete reduction has been yet to achieve. With utmost precautions about contaminants, fairly reliable data acquisition is under way in our laboratory. For example, the data obtained with screen-printed thick films of $\mathrm{SnO}_{2}$ of two different grain sizes (12 and $16 \mathrm{~nm}$ in diameter) at 300 and $350^{\circ} \mathrm{C}$ are shown in Figure 18. To check fitting between the data to the present theory, we need to know $R_{0}$ but it has been difficult to measure it precisely yet due to contaminant oxygen (about $100 \mathrm{ppm}$ in volume) in nitrogen. Here the resistance in nitrogen, $R\left(\mathrm{~N}_{2}\right)$, is substituted for $R_{0}$. The resistance data normalized by $R\left(\mathrm{~N}_{2}\right)$ are thus plotted as a function of square root of $P_{\mathrm{O}_{2}}$ in the figure. In spite of the ambiguity just mentioned, all the data at $300^{\circ} \mathrm{C}$ fall on a straight line fairly well in agreement with (25) or (34) derived for volume depletion. The data at $350^{\circ} \mathrm{C}$, however, falls on a line which is convex upward in the beginning and then becomes linear, a feature characteristic to a change from regional depletion to volume depletion. From the slope of each straight line, full or partial, and grain size, we can deduce $K_{\mathrm{O}_{2}}$ using (25) or (34). The slopes for $12 \mathrm{~nm}$ and $16 \mathrm{~nm}$ grains are 157 and $118 \mathrm{~nm} \mathrm{~atm}^{-1 / 2}$ at $300^{\circ} \mathrm{C}$, respectively, both giving $K_{\mathrm{O}_{2}}=$ $9.9 \times 10^{4} \mathrm{~nm}^{2} \mathrm{~atm}^{-1}$. The corresponding data at $350^{\circ} \mathrm{C}$ are 


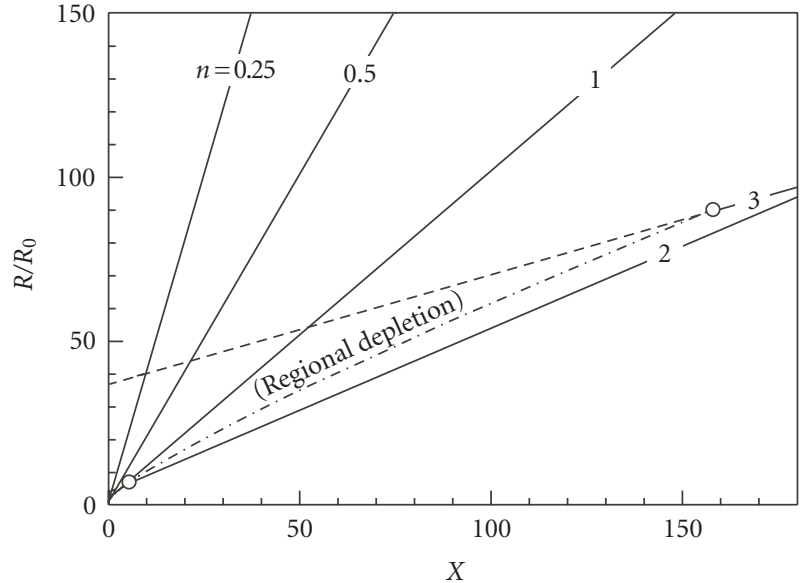

○ Boundary depletion

(a)

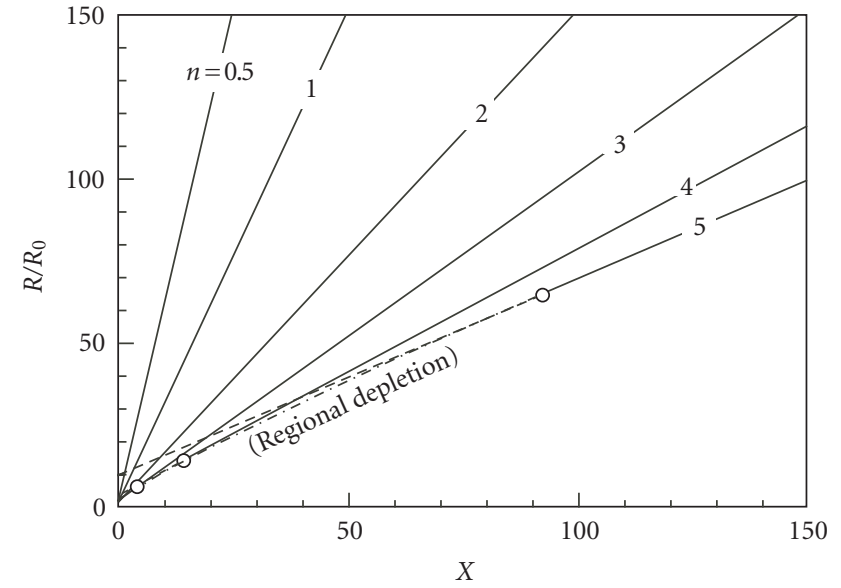

○ Boundary depletion

(b)

Figure 17: Correlations between $R / R_{0}$ and $X$ for plate crystals (a) and spherical crystals (b) with reduced size $n$ [15].

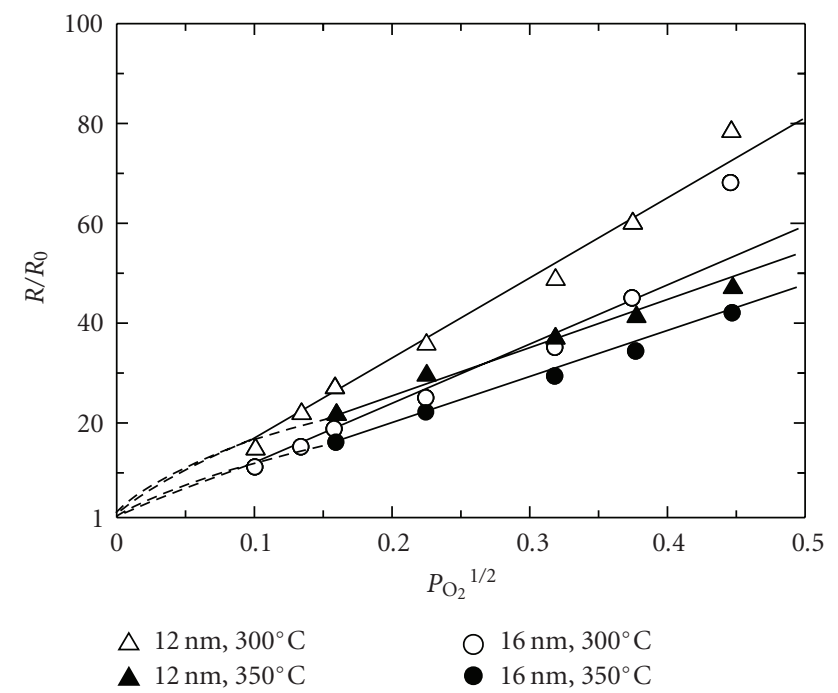

Figure 18: Normalized response to oxygen, $R / R\left(\mathrm{~N}_{2}\right)$, at two designated temperatures as correlated with $P_{\mathrm{O}_{2}}{ }^{1 / 2}$ for two screenprinted $\mathrm{SnO}_{2}$ thick film devices different in grain size. $R\left(\mathrm{~N}_{2}\right)$; resistance in $\mathrm{N}_{2}$.

89 and $83 \mathrm{~nm}$ atm $^{-1 / 2}$, giving $K_{\mathrm{O}_{2}}=3.1$ and 4.9 in unit of $10^{4} \mathrm{~nm}^{2} \mathrm{~atm}^{-1}$, respectively. In principle, $K_{\mathrm{O}_{2}}$ is independent of grain sizes and this is in fact confirmed with these experimental data. These results are fairly satisfactory and seem to assure the soundness of the present theory.

Let us consider next the grain size effect on $R_{a}$ already shown in Figure 4. The same data are plotted on logarithmic scales in Figure 19. When volume depletion is assumed to prevail in the whole grains size range tested, $R a / R_{0}$ is inversely proportional to $a$ according to (23) or (34), while it can be shown that $R_{0}$ is also inversely proportional to $a$ if ideal packing of spheres is assumed. As a result, $R_{a}$ should be essentially constant regardless of the variation of $a$. In fact, this is confirmed in the range of $a$ above $3.5 \mathrm{~nm}\left(a_{c}\right)$. The

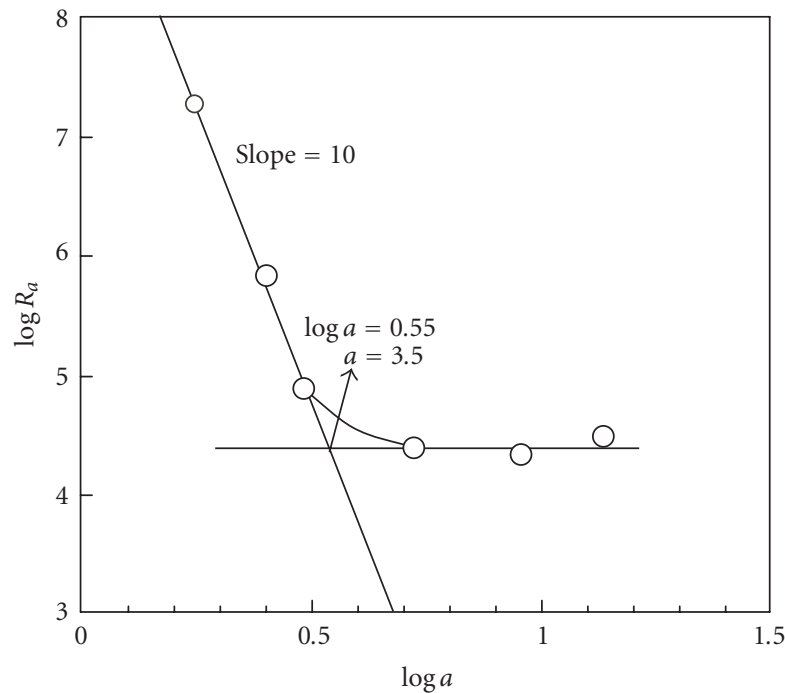

FIGURE 19: Grain size effect on Ra shown in Figure 4 as reproduced on the logarithmic scales [16].

sharp increase of $R_{a}$ observed with decreasing $a$ below $a_{c}$ can be attributed to an increase in the number of grains without donors (insulating grains). This can happen when the grain size (diameter) is made smaller than an average separation between neighboring donors under the condition of a fixed donor density $\left(N_{d}\right)$. From $a_{c}, N_{d}$ is estimated to be $5.6 \times$ $10^{18} \mathrm{~cm}^{-3}$, which is fairly close to reported values mentioned before. This in turn leads to $L_{D}=2.4 \mathrm{~nm}$ at $600 \mathrm{~K}$. In this way, the grain size effect on base resistance is understood in a way largely different from what was imagined in the past.

\section{Receptor Function and Response to $\mathrm{NO}_{2}$}

4.1. Modeling. $\mathrm{NO}_{2}$ is selected here as a representative of oxidizing gases which are adsorbed as negatively charged ions 
on the semiconductor surface. As generally accepted, it is assumed to undergo adsorption as follows:

$$
\mathrm{NO}_{2}+e=\mathrm{NO}_{2}^{-}
$$

The equilibrium of adsorption is written down:

$$
K_{\mathrm{NO}_{2}} P_{\mathrm{NO}_{2}}[e]_{S}=\left[\mathrm{NO}_{2}^{-}\right]
$$

$K_{\mathrm{NO}_{2}}$ and $P_{\mathrm{NO}_{2}}$ are the adsorption constant and the partial pressure of $\mathrm{NO}_{2}$, respectively, and $\left[\mathrm{NO}_{2}^{-}\right]$is the surface density of $\mathrm{NO}_{2}^{-}$. As noted, (R2) and (36) are quite similar to the corresponding equations for $\mathrm{O}_{2},(\mathrm{R} 1)$ and (8). This means that, in the absence of oxygen, receptor function and response to $\mathrm{NO}_{2}$ can be treated in exactly the same way as done to oxygen so far. That is, if we define the reduced adsorptive strength of $\mathrm{NO}_{2}$ as $Z=K_{\mathrm{NO}_{2}} P_{\mathrm{NO}_{2}} / L_{D}$, all of the correlations between $R / R_{0}$ and $X\left(=\left(K_{\mathrm{O}_{2}} P_{\mathrm{O}_{2}}\right)^{1 / 2} / L_{D}\right)$ obtained to $\mathrm{O}_{2}$ above can be transferred to the correlations to $\mathrm{NO}_{2}$ by replacing $X$ by $Z$.

In the coexistence of oxygen, we are placed in a different situation. Now both $\mathrm{O}_{2}$ and $\mathrm{NO}_{2}$ are adsorbed on the surface of crystals to compete for electrons. The mass action laws for $\mathrm{O}_{2}$ and $\mathrm{NO}_{2},(8)$ and (36), should be satisfied simultaneously. That is,

$$
\left[\mathrm{O}^{-}\right]+\left[\mathrm{NO}_{2}^{-}\right]=\left\{\left(K_{\mathrm{O}_{2}} P_{\mathrm{O}_{2}}\right)^{1 / 2}+K_{\mathrm{NO}_{2}} P_{\mathrm{NO}_{2}}\right\}[e]_{S} .
$$

This is a requirement from the chemistry side. In the physics side, it is required to have Fermi level kept the same at any sites among $\mathrm{O}^{-}, \mathrm{NO}_{2}^{-}$, and bulk of crystal in the band energy diagram, and nothing else is changed except that the total surface charge density is now contributed by the two kinds of adsorbates:

$$
\frac{-Q_{\mathrm{SC}}}{q}=\left[\mathrm{O}^{-}\right]+\left[\mathrm{NO}_{2}^{-}\right]
$$

As a result, all the equations involving $X$ so far derived to oxygen can survive if $X$ is replaced by $X+Z$. That is, the response of plate crystals (half thickness $a$ ) is expressed as follows.

\section{Regional depletion.}

$$
\begin{aligned}
X+Z & =m \exp \left(\frac{m^{2}}{2}\right), \\
\frac{R}{R_{0}} & =\exp \left(\frac{m^{2}}{2}\right) .
\end{aligned}
$$

\section{Volume depletion.}

$$
\frac{R}{R_{0}}=\frac{(X+Z)}{n}=\frac{\left\{\left(K_{\mathrm{O}_{2}} P_{\mathrm{O}_{2}}\right)^{1 / 2}+K_{\mathrm{NO}_{2}} P_{\mathrm{NO}_{2}}\right\}}{a} .
$$

The meaning of (39) is the same as before; $X+Z$ determines $m$ unequely and then does $R / R_{0}$ also unequely. Naturally, the correlations between $R / R_{0}$ and $X$ shown in Figure 15 are in effect in this case, too, if the abscissa is redefined to be $X+Z$.

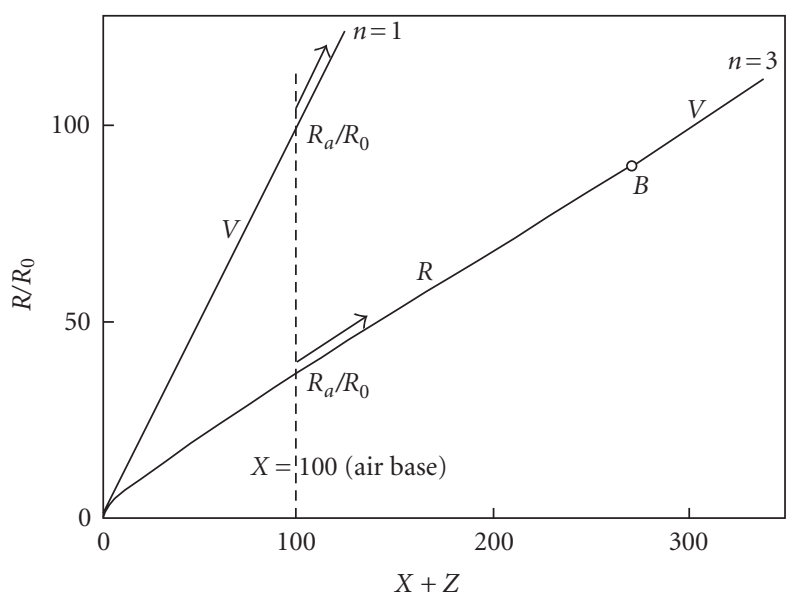

Figure 20: Correlations between $R / R_{0}$ and $X+Z$ derived for plate crystals [17].

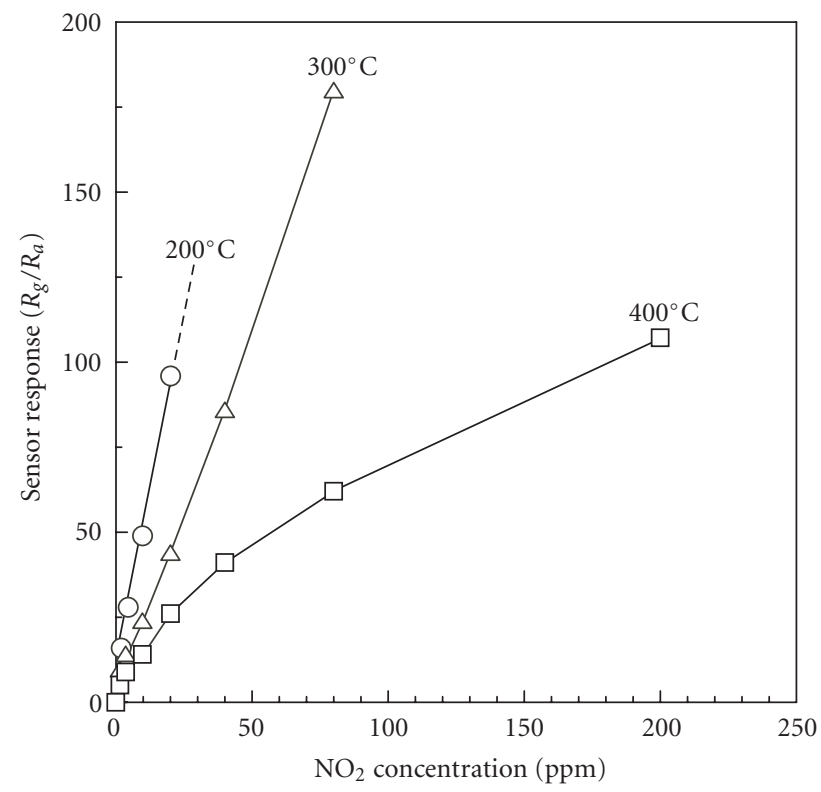

Figure 21: Sensor response to $\mathrm{NO}_{2}$ at designated temperatures as correlated with $\mathrm{NO}_{2}$ concentrations for granular $\mathrm{WO}_{3}$ crystals prepared by pyrolysis [16].

Correlations in the stage of volume depletion can be derived for other shapes of crystals and are summarized as follows:

$$
\begin{gathered}
\frac{R}{R_{0}}=(X+Z)\left(\frac{S}{n}\right)=\left\{\left(K_{\mathrm{O}_{2}} P_{\mathrm{O}_{2}}\right)^{1 / 2}+K_{\mathrm{NO}_{2}} P_{\mathrm{NO}_{2}}\right\}\left(\frac{S}{a}\right), \\
S=1 \text { (plate), } 2 \text { (column), and } 3 \text { (sphere). }
\end{gathered}
$$

4.2. Response to $\mathrm{NO}_{2}$ in Air. In the sensory measurement in air, $P_{\mathrm{O}_{2}}$ is fixed at $P_{\mathrm{O}_{2}}$ (air) and this determines the resistance level in air (air base), $R_{a} / R_{0}$. Conventionally, sensor response has often been defined as the ratio of device resistance in gas $\left(R_{g}\right)$ to that in air $\left(R_{a}\right)$. The conventional response $\left(R_{g} / R_{a}\right)$ 


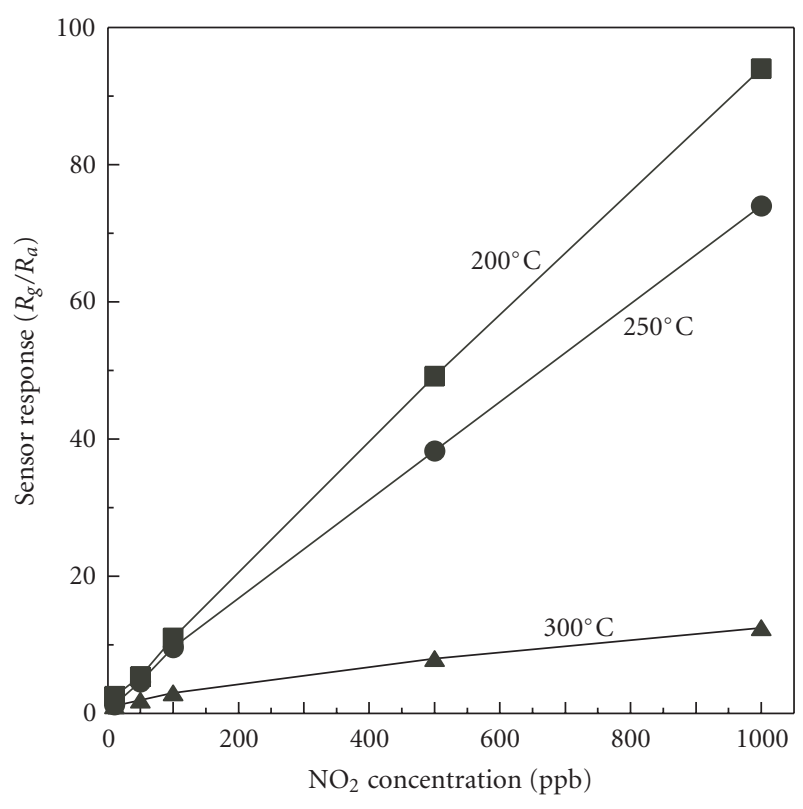

Figure 22: Sensor response to $\mathrm{NO}_{2}$ at designated temperatures as correlated with $\mathrm{NO}_{2}$ concentrations for lamellar $\mathrm{WO}_{3}$ crystals prepared by wet process [16].

thus defined corresponds to the ratio of the response to $X+Z$ to that to $X$ in the present treatment as follows:

$$
\frac{R_{g}}{R_{a}}=\frac{\left(R_{g} / R_{0}\right)}{\left(R_{a} / R_{0}\right)}
$$

Let us consider the meaning of this using Figure 20, which depicts the correlations between $R / R_{0}$ and $X+Z$ for plates of two different thicknesses $(n=1$ and 3$)$. If $X$ is assumed to take a value of 100 , the air base $\left(R_{a} / R_{0}\right)$ for $n=1$ is already on a linear correlation line of volume depletion, and addition of $Z$ simply increases the response along with the same line. From (40) or (41), we can derive

$$
\frac{R_{g}}{R_{a}}=\left\{\frac{K_{\mathrm{NO}_{2}} P_{\mathrm{NO}_{2}}}{\left(K_{\mathrm{O}_{2}} P_{\mathrm{O}_{2}}\right)^{1 / 2}}\right\}+1 .
$$

In this case the conventional response reflects the ratio of adsorptive strengths of the two components. In the case of thicker plates $(n=3)$, on the other hand, the air base point is still in the stage of regional depletion and, with an increase of $Z$, the response goes up toward volume depletion. The conventional response cannot be expressed in a simple equation like (43). The convex nature of the correlation lines tends to increase when the modified model is used (Figure 17), making the conventional response more nonlinear.

4.3. Comparison with Experiments. It has been shown that $\mathrm{WO}_{3}$ is very sensitive to $\mathrm{NO}_{2}$, though the sensitivity depends heavily on the methods of fabricating devices. Conventional sensor responses to $\mathrm{NO}_{2}$ observed with two devices different in fabrication method are shown in Figures 21 and 22. For the former device, $\mathrm{WO}_{3}$ was prepared from ammonium paratungstate through pyrolysis at $600^{\circ} \mathrm{C}$ for 5 hours and the resulting crystals were granular (grain size not measured) [40]. The response is seen to be linear to $P_{\mathrm{NO}_{2}}$ in the tested range up to $80 \mathrm{ppm}$ at 200 and $300^{\circ} \mathrm{C}$ but it changes to be apparently nonlinear at $400^{\circ} \mathrm{C}$. On the basis of the present theory, the linear response at the lower temperatures reflects volume depletion, while that at the highest temperature does regional depletion. This change is easily understood from Figure 17(b) (after replacing $X$ by $X+Z$ ) if we assume that $Z$ is much larger than $X$, while $K_{\mathrm{NO}_{2}}$ decreases exponentially with increasing temperature.

In the case of Figure 22, $\mathrm{WO}_{3}$ was prepared through a solgel process into shape of thin lamellae (ca $30 \mathrm{~nm}$ thick) [41]. The sensor response is seen to be linear at both temperatures of 200 and $250^{\circ} \mathrm{C}$ reflecting the involvement of volume depletion. It is as high as being able to detect $\mathrm{NO}_{2}$ down to a level of $10 \mathrm{ppb}$ at $200^{\circ} \mathrm{C}$. Such high sensitivity comes from the smallness of lamellar size used, as understood from (40). From (40) and (42), the slope of each correlation, 9.4 or 7.4 in unit of $10^{7} \mathrm{~nm} \mathrm{~atm}^{-1}$, respectively, gives rise to $\left(K_{\mathrm{NO}_{2}} / a\right) /\left(R_{a} / R_{0}\right)$. Thus we can estimate $K_{\mathrm{NO}_{2}}$ if $R_{a} / R_{0}$ is known. Unfortunately, this value is not known yet, but even when $R_{a} / R_{0}$ is assumed to take an ultimately small value of unity, $K_{\mathrm{NO}_{2}}$ can amount to a value as large as 1.4 or 1.1 in unit of $10^{9} \mathrm{~nm} \mathrm{~atm}^{-1}$, respectively. This confirms extremely strong nature of $\mathrm{NO}_{2}$ adsorption.

\section{Response to Hydrogen}

5.1. Modeling. Hydrogen is selected here as a representative of reducing gases, which decreases the device resistance. It is unanimous that $\mathrm{H}_{2}$ molecules react with $\mathrm{O}^{-}$adsorbates on the semiconductor crystals. We assume that $\mathrm{H}_{2}$ molecules collide directly with $\mathrm{O}^{-}$ions (Eley-Rideal mechanism) and $\mathrm{H}_{2} \mathrm{O}$ molecules formed are desorbed instantly from the surface:

$$
\mathrm{O}^{-}+\mathrm{H}_{2}=\mathrm{H}_{2} \mathrm{O}+e .
$$

This reaction consumes $\mathrm{O}^{-}$ions, while they are resupplied from the gas phase through the reaction, (R1).

The rate of accumulation of $\left[\mathrm{O}^{-}\right]$is expressed by

$$
\frac{d\left[\mathrm{O}^{-}\right]}{d t}=k_{1} P_{\mathrm{O}_{2}}[e]_{S}-k_{-1}\left[\mathrm{O}^{-}\right]^{2}-k_{3} P_{\mathrm{H}_{2}}\left[\mathrm{O}^{-}\right] .
$$

Here $t$ is time, $k_{1}$ and $k_{-1}$ are the rate constants of forward and reverse reactions of (R1), respectively, $k_{3}$ is that of forward reaction of (R3), and $P_{\mathrm{H}_{2}}$ is the partial pressure of $\mathrm{H}_{2}$. At steady state, $d\left[\mathrm{O}^{-}\right] / d t=0$, so that we obtain

$$
\left(K_{\mathrm{O}_{2}} P_{\mathrm{O}_{2}}\right)^{1 / 2}[e]_{S}=\left[\mathrm{O}^{-}\right]\left\{1+\left(\frac{c P_{\mathrm{H}_{2}}}{\left[\mathrm{O}^{-}\right]}\right)\right\}^{1 / 2} .
$$

Here $K_{\mathrm{O}_{2}}=k_{1} / k_{-1}$ (equilibrium adsorption constant) and $c=k_{3} / k_{-1}$. In the absence of $\mathrm{H}_{2}$, this equation coincides with the mass action law of the oxygen adsorption equilibrium, (8). This means that the presence of $\mathrm{H}_{2}$ modifies the value of $\left[\mathrm{O}^{-}\right]$simply according to (45). The electrostatic equilibrium 


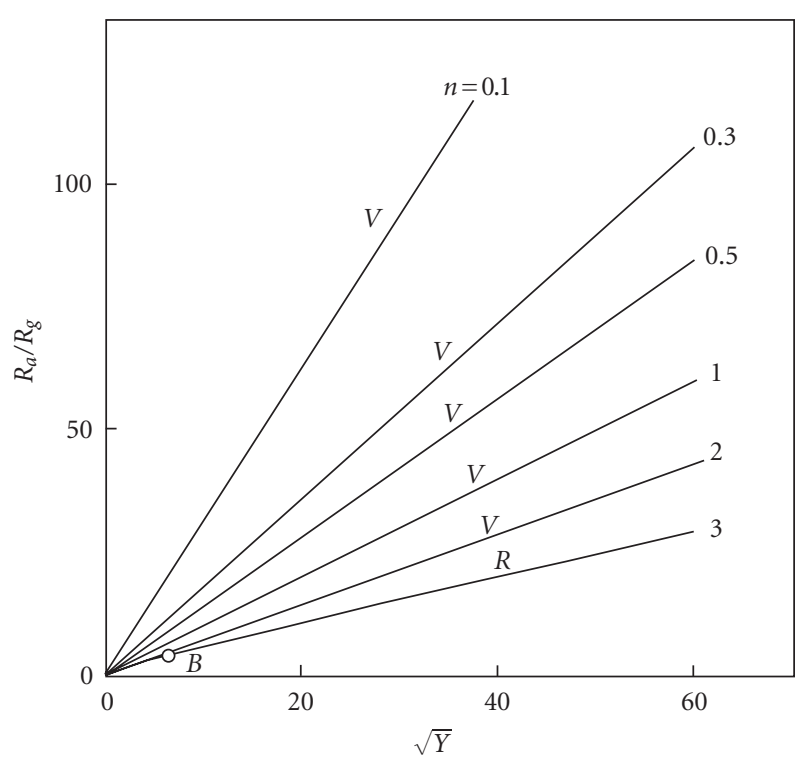

FIGURE 23: Theoretical sensor response to $\mathrm{H}_{2}$ as correlated with $Y^{1 / 2}$ at $X=1000$ [17].

of the crystal, on the other hand, does not see $\mathrm{H}_{2}$ but $\left[\mathrm{O}^{-}\right]$, requiring the depletion depth to change correspondingly. Thus the equations relating $V_{S}$ and $\left[\mathrm{O}^{-}\right]$with $m, n$, and $p$ in Section 3 can survive altogether in this new situation. Inserting those into (45) followed by rearrangement, we obtain an equation relating among $X\left(=\left(K_{\mathrm{O}_{2}} P_{\mathrm{O}_{2}}\right)^{1 / 2} / L_{D}\right)$, $Y\left(=\left(c / L_{D} N_{d}\right) P_{\mathrm{H}_{2}}\right)$, and $m$, while $R / R_{0}$ is always derived from $V_{S}$. The sensor resistance measured to a mixture of $\mathrm{H}_{2}$ and oxygen is expressed here as $R_{g}$ in order to distinguish it from that measured to oxygen only. The sought correlations for plates can be summarized as follows.

\section{Regional depletion.}

$$
\begin{gathered}
X \exp \left(\frac{-m^{2}}{2}\right)=m\left\{1+\left(\frac{1}{m}\right) Y\right\}^{1 / 2}, \\
\frac{R_{g}}{R_{0}}=\exp \left(\frac{m^{2}}{2}\right) \quad \text { (Plate). }
\end{gathered}
$$

Volume depletion.

$$
\begin{gathered}
\frac{R_{g}}{R_{0}}=\frac{S(X / n)}{\{1+(S / n) Y\}^{1 / 2}}, \\
S=1 \text { (plate), } 2 \text { (column), and } 3 \text { (sphere). }
\end{gathered}
$$

These equations show that under fixed $X$ (or $P_{\mathrm{O}_{2}}$ ), $R_{g} / R_{0}$ is an implicit or explicit function of $Y$. The equations in the stage of regional depletion for other shapes are excluded here for brevity.

5.2. Response to $\mathrm{H}_{2}$ in Air. In usual sensor operation, $P_{\mathrm{O}_{2}}$ is fixed at that $(0.21 \mathrm{~atm})$ of the air. Sensor response is often

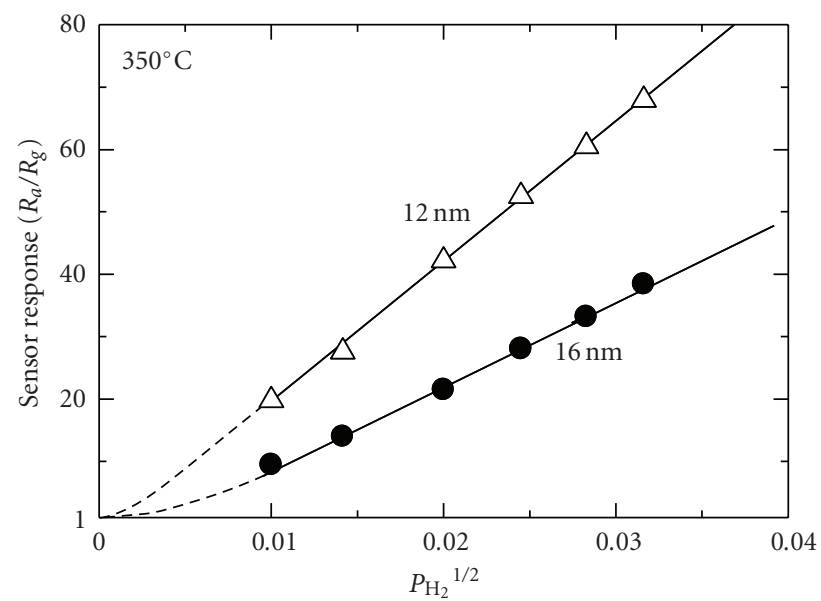

Figure 24: Observed sensor response to $\mathrm{H}_{2}$ in air at $350^{\circ} \mathrm{C}$ as correlated with $P_{\mathrm{H}_{2}}{ }^{1 / 2}$ for $\mathrm{SnO}_{2}$ devices different in grain size (screen-printed thick films).

defined as the ratio of the device resistance in air to that in the target gas (or normalized conductance), $R_{a} / R_{g}$. This corresponds to the response ratio in the present treatment as follows:

$$
\frac{R_{a}}{R_{g}}=\frac{\left(R_{a} / R_{0}\right)}{\left(R_{g} / R_{0}\right)} .
$$

Each term in the right-hand side can be estimated as a function of $Y$ for fixed $X$ by (46) or (47) so that the conventional sensor response can also be done. For example, Figure 23 shows the sensor response as a function of $Y^{1 / 2}$ for plate crystals, where $n$ is selected between 0.1 and 3 and $X$ is fixed at 1000 . As easily understood, even when a large $X$ is selected in order to secure deep stages of volume depletion in the absence of $\mathrm{H}_{2}$, the crystals are brought to regional depletion ultimately on increasing $Y$, and this tendency is enhanced with increasing $n$. Regional depletion is seen to begin at a relatively small value of $Y^{1 / 2}$ for $n=3$. In the range of $Y^{1 / 2}$ where volume depletion prevails, (47) holds so that (48) is transformed into an explicit function of $Y$ :

$$
\frac{R_{a}}{R_{g}}=\left\{1+\left(\frac{1}{n}\right) Y\right\}^{1 / 2}=\left\{1+\left(\frac{c}{a N_{d}}\right) P_{\mathrm{H}_{2}}\right\}^{1 / 2} .
$$

When $\left(c / a N_{d}\right) P_{\mathrm{H}_{2}}$ is far larger than unity,

$$
\frac{R_{a}}{R_{g}}=\left\{\frac{Y}{n}\right\}^{1 / 2}=\left\{1+\left(\frac{c}{a N_{d}}\right) P_{\mathrm{H}_{2}}\right\}^{1 / 2} .
$$

This is why linear correlations appear in the range of volume depletion as shown. In the range of regional depletion, such linearity is not allowed, though detailed discussion is reserved here.

5.3. Comparison with Experiments. Sensor response $\left(R_{a} / R_{g}\right)$ of two screen-coated $\mathrm{SnO}_{2}$ thick film devices different in grain size ( 12 and $16 \mathrm{~nm}$ in diameter) to $\mathrm{H}_{2}$ at $350^{\circ} \mathrm{C}$ is shown as a function of $P_{\mathrm{H}_{2}}{ }^{1 / 2}$ in Figure 24. The response 


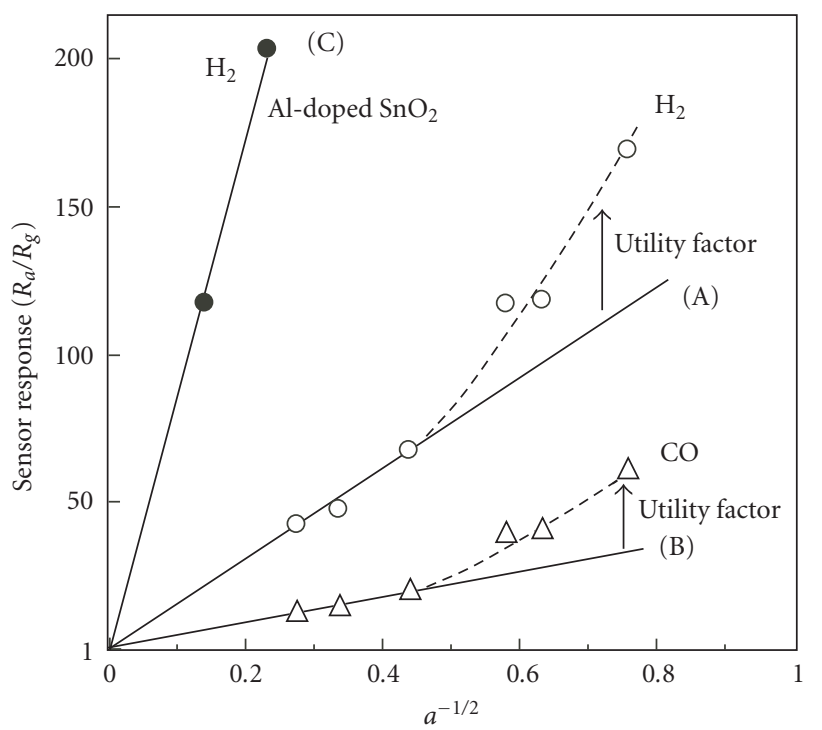

FIGURE 25: Grain size effect on sensor response shown in Figure 4 as reproduced in the relation between $R_{a} / R_{g}$ and $a^{-1 / 2}$.

data of each device fall on a correlation line which is slightly concave upward initially and then becomes almost straight. This behavior is easily understood from (46)-(50). For example, (49) and (50) show that the linear relation is obtained when $P_{\mathrm{H}_{2}}$ is sufficiently large, and otherwise the concaved relation comes out. It is noted that the response as well as the slope of the correlation are lager with the smaller $\mathrm{SnO}_{2}$ grains. This is also consistent with what is expected from the derived equations. It is reserved, however, that really quantitive analysis of the response behavior is not mature yet at present because of a lack of knowledge about many physicochemical constants needed. Probably we have to go up spirally repeating measurements and theoretical analyses.

Finally let us consider the grain size effects previously shown in Figure 4. The response data are reproduced in Figure 25, where the response is plotted against reciprocal of square root of $a$. Three data of the larger grains to either $\mathrm{H}_{2}$ (A) or CO (B) fall on a straight line passing through origin in agreement with (50), while the remaining data on the smaller grains deviate upward probably through improvements of utility factor due to the appearance of insulating grains. The ratio of the slopes of straight lines, $\mathrm{A} / \mathrm{B}$, gives the ratio of the rate constants $\left(k_{2}\right)$ of the oxidation reactions of $\mathrm{H}_{2}$ and $\mathrm{CO}$. The ratio is analyzed to be 14 . Similar response data to $\mathrm{H}_{2}$ (C) measured with Al-doped $\mathrm{SnO}_{2}$ [42] are also included in the figure. The slope ratio, $\mathrm{C} / \mathrm{A}$, which is $1 / 29$ in this case, gives the ratio of donor density $\left(N_{d}\right)$.

\section{Influences of Electron-Traps Dispersed on the Crystals Surface (Plates)}

6.1. Modeling of Receptor Function. Semiconductor gas sensors are usually sensitized by loading the constituent crystals with sensitizers, as mentioned before. Among a variety of sensitizers known, we consider here only those which draw electrons from the constituent crystals, increasing work

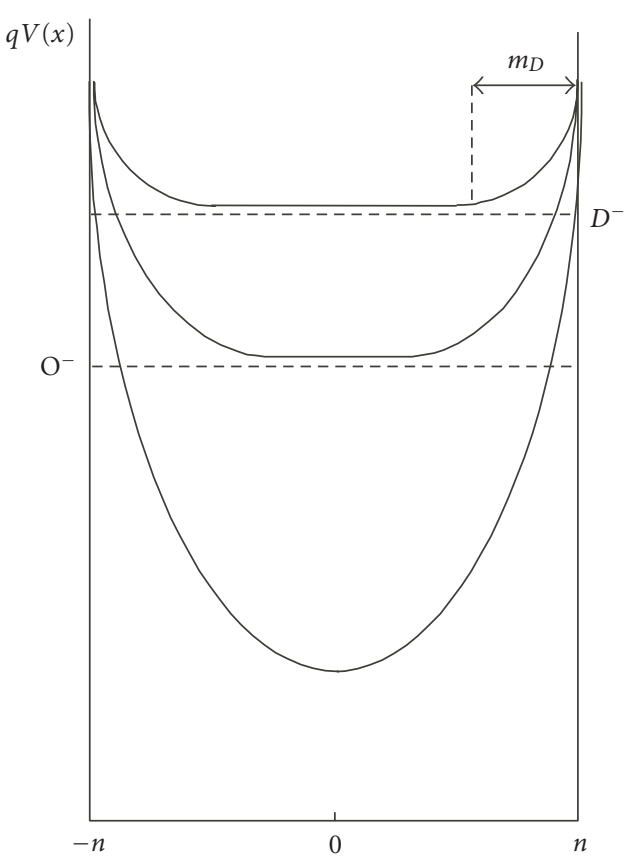

FIGURE 26: Diagram of electrostatic equilibrium drawn for small crystals loaded with surface electron-traps.

function of the crystals. Further, only the event of electron transfer between the sensitizers and the crystals is focused attention, excluding any other events such as redox changes of the sensitizers. It is assumed that the sensitizer in problem is deposited as tiny particles or clusters (denoted $D$ ), which form electron-trapping centers located in the forbidden band at the surface. Electrons would be transferred from the crystals to form ionized traps $\left(D^{-}\right)$. Unlike the case of gas adsorption, however, the electrons once trapped do not return back to the crystals no matter how gas atmosphere changes, if the trapping level is deep enough. In the treatment of electrostatic equilibrium, $D^{-}$contributes to the total surface charge density $\left(Q_{s}\right)$ together with ionized adsorbates, typically $\mathrm{O}^{-}$and/or $\mathrm{NO}_{2}^{-}$, as shown in Figure 26 . For plate crystals placed in air, this is expressed as

$$
Q_{s}=-q\left(\left[D^{-}\right]+\left[\mathrm{O}^{-}\right]\right)=-q m L_{D} N_{d} .
$$

Here $m$ is the reduced depletion depth in air. Obviously the presence of $\left[D^{-}\right]$affects $m$ depending on its magnitude. For ease of treatment, $\left[D^{-}\right]$is expressed in terms of reduced depletion depth, $m_{D}$, it develops in the absence of oxygen. That is,

$$
\left[D^{-}\right]=m_{D} L_{D} N_{d}
$$

Two cases are distinguished here depending on whether the electron transfer between the traps and the bulk of crystals is reversible (reversible traps) or not (irreversible traps).

In the case of reversible traps, trapped electrons participate in the electrostatic equilibrium of the crystals; $\left[D^{-}\right]$, $\left[\mathrm{O}^{-}\right]$, and the bulk of each crystal are kept at the same Fermi level. By using (8) and (52), (51) is rewritten as

$$
m_{D} L_{D} N_{d}+\left(K_{\mathrm{O}_{2}} P_{\mathrm{O}_{2}}\right)^{1 / 2}[e]_{s}=m L_{D} N_{d}
$$




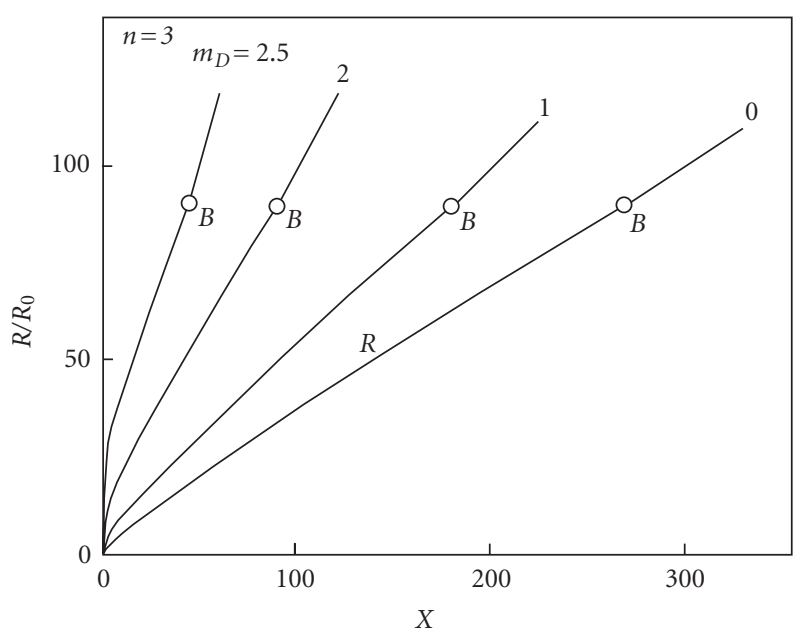

FIgure 27: Correlations between $R / R_{0}$ and $X$ for plate crystals dispersed with reversible electron-traps [17].

It is reminded that $m$ and $m_{D}$ are reduced depletion depths to $\left[D^{-}\right]+\left[\mathrm{O}^{-}\right]$and $\left[D^{-}\right]$, respectively. We know that $[e]_{s}$ as well as $R / R_{0}$ are expressed as a function of $m, n$, and $p$. The following equations result for correlating $R / R_{0}$ with $X$ (abrupt model).

Regional depletion.

$$
\begin{gathered}
X \exp \left(\frac{-m^{2}}{2}\right)=m-m_{D}, \\
\frac{R}{R_{0}}=\exp \left(\frac{m^{2}}{2}\right) .
\end{gathered}
$$

Volume depletion.

$$
\frac{R}{R_{0}}=\exp \left\{\left(\frac{n^{2}}{2}\right)+p\right\}=\frac{X}{\left(n-m_{D}\right)}
$$

The correlations derived for $m_{D}=0,1,2$, and 2.5 , and $n=3$ are shown in Figure 27. For given $X, R / R_{0}$ increases dramatically with increasing $m_{D}$. In the stage of volume depletion, $R / R_{0}$ of a trap-dispersed plate of reduced size $n$ is the same as that exhibited by a clean plate of reduced size $n-m_{D}$. The response in the stage of regional depletion is seen to be also enhanced dramatically on increasing $m_{D}$.

In the case of irreversible traps, trapped electrons are assumed to stay at the traps permanently. It is suspected that such case may happen when the foreign deposits react with the surface of the constituent crystals. For example, the component cations of the deposits are dissolved into the lattice of underlying crystals at the surface or nearby. The dissolved cations may act as strong acceptors of electrons (irreversible traps). Anyway those trapped electrons amounting to depth $m_{D}$ are kept off from the electrostatic equilibrium. As a result, oxygen adsorption cannot take place until $P_{\mathrm{O}_{2}}$ exceeds a

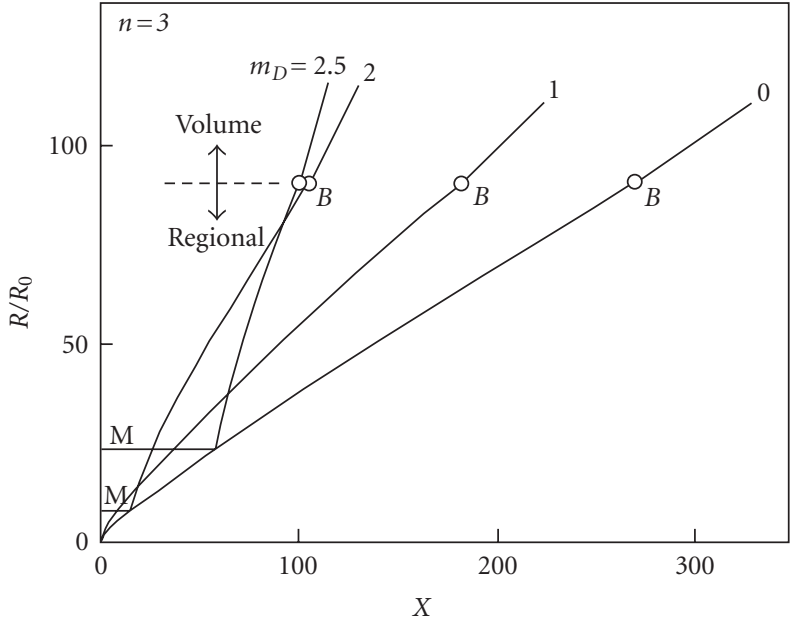

M: Masking

Figure 28: Correlations between $R / R_{0}$ and $X$ for plate crystals dispersed with irreversible electron-traps [17].

critical point $\left(P_{\mathrm{O}_{2}}(D)\right)$ at which depletion depth reaches $m_{D}$ in the absence of $\left[D^{-}\right]$. Equation (51) is rewritten as

$$
\left[D^{-}\right]+\left\{\left(K_{\mathrm{O}_{2}} P_{\mathrm{O}_{2}}\right)^{1 / 2}-\left(K_{\mathrm{O}_{2}} P_{\mathrm{O}_{2}}(D)\right)^{1 / 2}\right\}[e]_{s}=m L_{D} N_{d}
$$

The resulting correlating equations are summarized as follows:

\section{Regional depletion.}

$$
\begin{gathered}
\left(X-X_{D}\right) \exp \left(\frac{-m^{2}}{2}\right)=m-m_{D}, \\
\frac{R}{R_{0}}=\exp \left(\frac{m^{2}}{2}\right) .
\end{gathered}
$$

Volume depletion.

$$
\begin{gathered}
(X-X D) \exp \left\{-\left(\frac{n^{2}}{2}\right)-p\right\}=n-m_{D}, \\
\frac{R}{R_{0}}=\exp \left\{\left(\frac{n^{2}}{2}\right)+p\right\}=\left(X-X_{D}\right)\left(n-m_{D}\right) .
\end{gathered}
$$

Here $X(D)=\left(K_{\mathrm{O}_{2}} P_{\mathrm{O}_{2}}(D)\right)^{1 / 2} / L_{D}$. The correlations given by these equations are shown in Figure 28, where $m_{D}$ and $n$ are set to the same values as those used in Figure 27. It is seen that the response does not appear up to $X=X_{D}$ (masking) and then rise up steeply with a slope increasing with increasing $m_{D}$. The irreversible traps are thus effective also in enhancing the sensitivity to $\mathrm{O}_{2}$, though in a manner different from that with the reversible traps.

6.2. Response to $\mathrm{NO}_{2}$ or $\mathrm{H}_{2}$ in Air. In this section, response of electron-trap dispersed plates to $\mathrm{NO}_{2}$ or $\mathrm{H}_{2}$ in air is discussed 


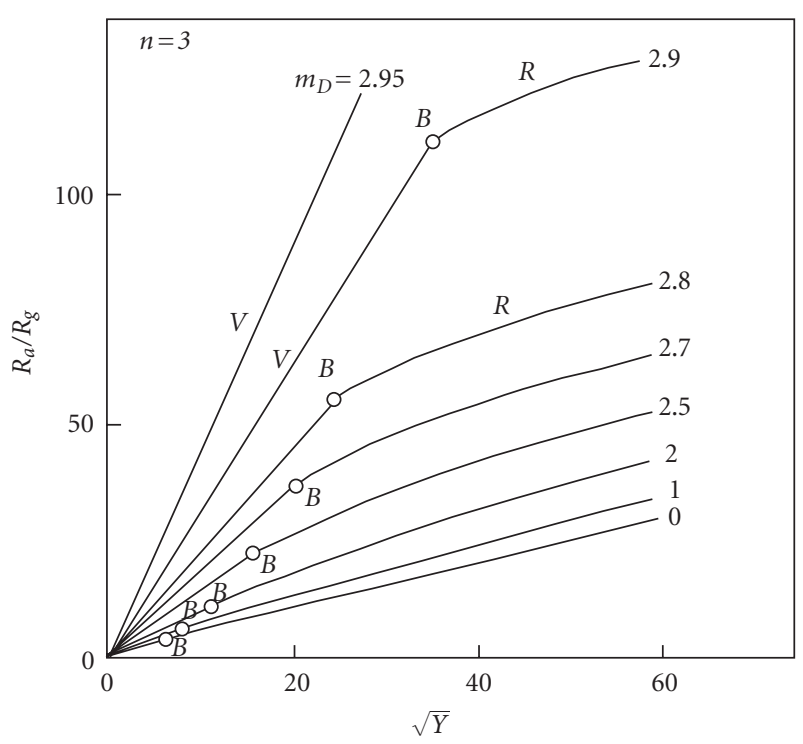

FIGURE 29: Correlations between $R_{a} / R_{g}$ and $Y^{1 / 2}$ for plate crystals dispersed with reversible electron-traps [17].

briefly. Under exposure to $\mathrm{NO}_{2}$ in air, total surface charge density is written as follows:

$$
Q_{s}=-q\left(\left[D^{-}\right]+\left[\mathrm{O}^{-}\right]+\left[\mathrm{NO}_{2}^{-}\right]\right)=-q m L_{D} N_{d}
$$

For either type of traps, reversible and irreversible, the sought correlations between $R / R_{0}$ and $X+Z$ are essentially the same as those obtained between $R / R_{0}$ and $X$ if $X$ is replaced by $X+Z$. At fixed $X$, the sensitivity of $R / R_{0}$ to $Z$ increases sharply with increasing $m_{D}$.

The response to $\mathrm{H}_{2}$ in air can be developed in the same way as done for clean plate crystals. $\left[\mathrm{O}^{-}\right]$is given by $(45)$, while $\left[D^{-}\right]$is kept constant. Using these equations, it is possible to derive the sought correlations for reversible traps as follows.

Regional depletion.

$$
\begin{aligned}
X \exp \left(\frac{-m^{2}}{2}\right)= & \left(m-m_{D}\right)\left\{1+\left[\frac{1}{\left(m-m_{D}\right)}\right] Y\right\}^{1 / 2}, \\
& \frac{R_{g}}{R_{0}}=\exp \left(\frac{m^{2}}{2}\right) .
\end{aligned}
$$

Volume depletion.

$$
\begin{aligned}
\frac{R_{g}}{R_{0}} & =\left\{\frac{X}{\left(n-m_{D}\right)}\right\}\left\{1+\left[\frac{1}{\left(n-m_{D}\right)}\right] Y\right\}^{1 / 2}, \\
\frac{R_{a}}{R_{g}} & =\left\{1+\left[\frac{1}{\left(n-m_{D}\right)}\right] Y\right\}^{1 / 2} \\
& =\left\{1+\left[\frac{1}{\left(n-m_{D}\right)}\right]\left[\frac{c}{L_{D} N_{d}}\right] P_{\mathrm{H}_{2}}\right\}^{1 / 2} .
\end{aligned}
$$

Equation (62) formulates conventional sensor response. The response is drastically promoted by increasing $m_{D}$, as illustrated in Figure 29, where correlations are sought between $R_{a} / R_{g}$ and $Y^{1 / 2}$ with $n$ and $X$ being fixed at 3 and 1000 , respectively. However, the manner of promotion of the response is considerably different from that of the thickness effect observed with clean plates (Figure 23).

In the case of irreversible traps, the correlations are given as follows.

Regional depletion.

$$
\begin{aligned}
\left(X-X_{D}\right) \exp \left(\frac{-m^{2}}{2}\right) & =\left(m-m_{D}\right)\left\{1+\left[\frac{1}{\left(m-m_{D}\right)}\right] Y\right\}^{1 / 2}, \\
\frac{R_{g}}{R_{0}} & =\exp \left(\frac{m^{2}}{2}\right) .
\end{aligned}
$$

Volume depletion.

$$
\begin{gathered}
\frac{R_{g}}{R_{0}}=\left\{\frac{\left(X-X_{D}\right)}{\left(n-m_{D}\right)}\right\}\left\{1+\left[\frac{1}{\left(n-m_{D}\right)}\right] Y\right\}^{-1 / 2}, \\
\frac{R_{a}}{R_{g}}=\left\{1+\left[\frac{1}{\left(n-m_{D}\right)}\right]\left[\frac{c}{L_{D} N_{d}}\right] P_{\mathrm{H}_{2}}\right\}^{1 / 2} .
\end{gathered}
$$

Expression of conventional sensor response (65) is seen to be identical to (62). This is quite natural because it does not matter in the stage of volume depletion whether the traps are reversible or not.

\section{Discussion}

To those who have been engaged in semiconductor gas sensor researches like us, it is a long-time dream to acquire a theoretical background of sensor researches. For a long time, many people have exerted efforts to upgrade capabilities of sensors or to extend applications of sensors empirically from various standpoints of sensing materials, material preparation and processing, sensitizers and stabilizers, sensing body structure and fabrication, device structure, electrodes, signal processing, transients based sensing, and so forth. These efforts have contributed to ever continuing progresses of gas sensors. However, it has not always been easy to understand well the meaning of a new progress achieved in a particular category, to those working in different categories. Even it has happened that the finders themselves do not understand their remarkable findings well, failing to connect them to another progress. All these have arisen mainly from a lack of a theoretical background commonly possessed by gas sensor researchers.

The theoretical concept available to semiconductor gas sensors has so far been almost nothing more than the concept of semiconductor catalysis born a long time ago. It has been useful for qualitative interpretations of gas sensors but almost powerless for quantitative analyses. A main reason for this is that the concept has ignored the role or meaning of so small semiconductors as used in gas sensors. Behavior of small semiconductors is considerably different from that 
of large ones and this difference provides gas sensors with profound merits. This is a truth unrevealed so far. We have shown in this article that gas response behavior of small semiconductors can be formulated by using wellestablished concepts and well-known parameters in physics and chemistry. The equations derived seem to work well on understanding the response behavior experimentally observed, though available data are still limited at present. No doubt the equations need to be checked more rigorously by experiments. Nevertheless we believe we are at a new starting point for theoretical approaches to semiconductor gas sensors. It is anticipated that such approaches will contribute much to strengthening and expanding the background of gas sensors. The treatments described in this article have focused attention to receptor function of semiconductors only, setting transducer function to work in a simple mode. Elaboration of the transducer function is one of the most important subjects of theoretical approaches.

\section{Conclusions}

Through the theoretical approaches to semiconductor gas sensors described here, the following conclusions can be drawn.

(1) Receptor function and response of small semiconductor crystals can be formulated in principle by using the chemical parameters of gases side, such as partial pressure, adsorption constant and rate constant, and the physical parameters of semiconductor side, such as shape and size, donor density, and Debye length.

(2) Theoretical equations account for well-response behavior to oxygen, nitrogen dioxide, and hydrogen, as well as the grain size effects involved, though the tested examples are limited in number.

(3) Electron-traps dispersed on the crystal surface influence strongly on receptor function and response to gases, thus exerting a kind of sensitization effect.

\section{List of parameters and symbols frequently used}

$\begin{array}{ll}K_{\mathrm{O}_{2}} \text { and } K_{\mathrm{NO}_{2}}: & \begin{array}{l}\text { Equilibrium adsorption } \\ \text { constants of } \mathrm{O}_{2} \text { and } \mathrm{NO}_{2}\end{array} \\ P_{\mathrm{O}_{2}}, P_{\mathrm{NO}_{2}} \text { and } P_{\mathrm{H}_{2}}: & \begin{array}{l}\text { Partial pressures of } \mathrm{O}_{2}, \mathrm{NO}_{2} \text { and } \\ \mathrm{H}_{2}\end{array} \\ P_{\mathrm{O}_{2}}(D): & \begin{array}{l}P_{\mathrm{O}_{2}} \text { giving } m_{D} \text { in the absence of } D \\ \text { Surface density of conduction } \\ {[e]_{s}:}\end{array} \\ {\left[\mathrm{O}^{-}\right],\left[\mathrm{NO}_{2}^{-}\right] \text {and }\left[D^{-}\right]: \begin{array}{l}\text { Surface densities of } \mathrm{O}^{-}, \mathrm{NO}_{2}^{-}, \\ \text {and } D^{-}\end{array}} \\ D \text { and } D^{-}: & \begin{array}{l}\text { Extrinsic electron-traps, neutral } \\ (D) \text { and ionized }\left(D^{-}\right)\end{array} \\ Q_{s}: & \begin{array}{l}\text { Total surface charge density } \\ q:\end{array} \\ N_{d} \text { and } \varepsilon: & \begin{array}{l}\text { Electric charge of proton } \\ \text { Donor density and permittivity }\end{array} \\ L_{D}: & \text { of oxide semiconductor } \\ a \text { and } n: & \text { Debye length } \\ & \text { Half thickness of plates and } \\ & \text { reduced thickness }\left(a / L_{D}\right)\end{array}$

$$
\begin{array}{ll}
w \text { and } m: & \begin{array}{l}
\text { Depletion depth and reduced } \\
\text { depletion depth }\left(w / L_{D}\right)
\end{array} \\
m_{D}: & \begin{array}{l}
\text { Reduced depletion depth in } \\
\text { vacuum due to extrinsic traps }
\end{array} \\
x \text { and } X: & \begin{array}{l}
\text { Displacement from origin and } \\
\text { reduced displacement }\left(x / L_{D}\right)
\end{array} \\
V(x), V(X), \text { and } V_{s}: & \text { Potential energy of electrons at } \\
& x, X \text { and surface } \\
p: & \text { Fermi level shift } \\
X: & =\left(K_{\mathrm{O}_{2}} P_{\mathrm{O}_{2}}\right)^{1 / 2} / L_{D} \\
Y: & =\left(c / L_{D} N_{d}\right) P_{\mathrm{H}_{2}} \\
Z: & =K_{\mathrm{NO}_{2}} P_{\mathrm{NO}_{2}} / L_{D} \\
X(D): & =\left(K_{\mathrm{O}_{2}} P_{\mathrm{O}_{2}}(D)\right)^{1 / 2} / L_{D} \\
c: & =k_{3} / k_{-1} \\
k_{1} \text { and } k_{-1}: & \text { Rate constants of oxygen } \\
& \text { adsorption and desorption }(\mathrm{R} 1) \\
k_{3}: & \text { Rate constant of surface reaction } \\
& (\mathrm{R} 3) \\
R \text { and } R_{0}: & \text { Resistances at } P_{\mathrm{O}_{2}} \text { and flat band } \\
R_{a} \text { and } R_{g}: & \text { state } \\
& \text { Resistances in air and target gas }
\end{array}
$$

\section{Acknowledgment}

The authors are grateful to Mr. Koichi Suematsu for providing them with experimental data on sensor response to oxygen and hydrogen.

\section{References}

[1] T. Seiyama, A. Kato, K. Fujiishi, and M. Nagatani, "A new detector for gaseous components using semiconductive thin films," Analytical Chemistry, vol. 34, no. 11, pp. 1502-1503, 1962.

[2] N. Taguchi, "Published patent application in Japan," S3747677, October 1962.

[3] G. Heiland, "Homogeneous semiconducting gas sensors," Sensors and Actuators, vol. 2, pp. 343-361, 1982.

[4] N. Yamazoe, "Toward innovations of gas sensor technology," Sensors and Actuators B, vol. 108, no. 1-2, pp. 2-14, 2005.

[5] K. Ihokura and J. Watson, The Stannic Oxide Gas Sensor: Principles and Applications, CRC Press, Japan, 1994.

[6] G. Korotcenkov, "The role of morphology and crystallographic structure of metal oxides in response of conductometric-type gas sensors," Materials Science and Engineering $R$, vol. 61, no. 1-6, pp. 1-39, 2008.

[7] Y. Shimizu and M. Egashira, "Basic aspects and challenges of semiconductor gas sensors," MRS Bulletin, vol. 24, no. 6, pp. 18-24, 1999.

[8] A. Gurlo, N. Barsan, and U. Weimar, Gas Sensors Based on Semiconducting Metal Oxides, Metal Oxides: Chemistry and Applications, Marcel Dekker, New York, NY, USA, 2004.

[9] M. Madou and S. R. Morrison, Chemical Sensing with Solid State Devices, Academic Press, Boston, Mass, USA, 1989.

[10] G. Sakai, N. Matsunaga, K. Shimanoe, and N. Yamazoe, "Theory of gas-diffusion controlled sensitivity for thin film semiconductor gas sensor," Sensors and Actuators B, vol. 80, no. 2, pp. 125-131, 2001.

[11] N. Matsunaga, G. Sakai, K. Shimanoe, and N. Yamazoe, "Diffusion equation-based study of thin film semiconductor gas sensor-response transient," Sensors and Actuators B, vol. 83, no. 1-3, pp. 216-221, 2002. 
[12] N. Matsunaga, G. Sakai, K. Shimanoe, and N. Yamazoe, "Formulation of gas diffusion dynamics for thin film semiconductor gas sensor based on simple reaction-diffusion equation," Sensors and Actuators B, vol. 96, no. 1-2, pp. 226233, 2003.

[13] N. Yamazoe, K. Shimanoe, and C. Sawada, "Contribution of electron tunneling transport in semiconductor gas sensor," Thin Solid Films, vol. 515, no. 23, pp. 8302-8309, 2007.

[14] N. Yamazoe and K. Shimanoe, "Theory of power laws for semiconductor gas sensors," Sensors and Actuators B, vol. 128, no. 2, pp. 566-573, 2008.

[15] N. Yamazoe and K. Shimanoe, "Roles of shape and size of component crystals in semiconductor gas sensors-I: response to oxygen," Journal of the Electrochemical Society, vol. 155 , no. 4, pp. J85-J92, 2008.

[16] N. Yamazoe and K. Shimanoe, "Roles of shape and size of component crystals in semiconductor gas sensors-II: response to $\mathrm{NO}_{2}$ and $\mathrm{H}_{2}$," Journal of the Electrochemical Society, vol. 155, no. 4, pp. J93-J98, 2008.

[17] N. Yamazoe and K. Shimanoe, "Receptor function of small semiconductor crystals with clean and electron-traps dispersed surfaces," Thin Solid Films. In press.

[18] M. Iwamoto, Y. Yoda, N. Yamazoe, and T. Seiyama, "Study of metal oxide catalysts by temperature programmed desorption 4. Oxygen adsorption on various metal oxides," Journal of Physical Chemistry, vol. 82, no. 24, pp. 2564-2570, 1978.

[19] N. Yamazoe, J. Fuchigami, M. Kishikawa, and T. Seiyama, "Interactions of tin oxide surface with $\mathrm{O}_{2}, \mathrm{H}_{2} \mathrm{O}$ and $\mathrm{H}_{2}$," Surface Science, vol. 86, pp. 335-344, 1979.

[20] Y. Mizokawa and S. Nakamura, "ESR and electric conductance studies of the fine-powdered $\mathrm{SnO}_{2}$," Japanese Journal of Applied Physics, vol. 14, no. 6, pp. 779-788, 1975.

[21] C. Xu, J. Tamaki, N. Miura, and N. Yamazoe, "Grain size effects on gas sensitivity of porous $\mathrm{SnO}_{2}$-based elements," Sensors and Actuators B, vol. 3, no. 2, pp. 147-155, 1991.

[22] Y.-G. Choi, G. Sakai, K. Shimanoe, N. Miura, and N. Yamazoe, "Wet process-prepared thick films of $\mathrm{WO}_{3}$ for $\mathrm{NO}_{2}$ sensing," Sensors and Actuators B, vol. 95, no. 1-3, pp. 258-265, 2003.

[23] A. Rothschild and Y. Komem, "On the relationship between the grain size and gas-sensitivity of chemo-resistive metaloxide gas sensors with nanosized grains," Journal of Electroceramics, vol. 13, no. 1-3, pp. 697-701, 2004.

[24] A. Rothschild and Y. Komem, "The effect of grain size on the sensitivity of nanocrystalline metal-oxide gas sensors," Journal of Applied Physics, vol. 95, no. 11, pp. 6374-6380, 2004.

[25] N. Barsan, "Conduction models in gas-sensing $\mathrm{SnO}_{2}$ layers: grain-size effects and ambient atmosphere influence," Sensors and Actuators B, vol. 17, no. 3, pp. 241-246, 1994.

[26] N. Barsan and U. Weimar, "Conduction model of metal oxide gas sensors," Journal of Electroceramics, vol. 7, no. 3, pp. 143 $167,2001$.

[27] M. Batzill and U. Diebold, "The surface and materials science of tin oxide," Progress in Surface Science, vol. 79, no. 2-4, pp. 47-154, 2005.

[28] J. Ding, T. J. McAvoy, R. E. Cavicchi, and S. Semancik, "Surface state trapping models for $\mathrm{SnO}_{2}$-based microhotplate sensors," Sensors and Actuators B, vol. 77, no. 3, pp. 597-613, 2001.

[29] H. Ogawa, M. Nishikawa, and A. Abe, "Hall measurement studies and an electrical conduction model of tin oxide ultrafine particle films," Journal of Applied Physics, vol. 53, no. 6, pp. 4448-4455, 1982.

[30] H. Ohnishi, "Current state and subjects of gas sensor technology in city gas industries," Materials Integration, vol. 21, no. 5, pp. 167-177, 2008.
[31] S. Matsushima, J. Tamaki, N. Miura, and N. Yamazoe, "TEM observation of the dispersion state of $\mathrm{Pd}$ on $\mathrm{SnO}_{2}$," Chemistry Letters, vol. 18, no. 9, pp. 1651-1654, 1989.

[32] N. Yamazoe, "New approaches for improving semiconductor gas sensors," Sensors and Actuators B, vol. 5, no. 1-4, pp. 7-19, 1991.

[33] S. Matsushima, Y. Teraoka, N. Miura, and N. Yamazoe, "Electronic interaction between metal additives and tin dioxide in tin dioxide-based gas sensors," Japanese Journal of Applied Physics, vol. 27, no. 10, pp. 1798-1802, 1988.

[34] P. B. Weisz, "Effects of electronic charge transfer between adsorbate and solid on chemisorption and catalysis," The Journal of Chemical Physics, vol. 21, no. 9, pp. 1531-1538, 1951.

[35] T. Wolkenstein, The Electron Theory of Catalysis on Semiconductors, Pergamon Press, Oxford, UK, 1963.

[36] H. Eyring, D. Henderson, and W. Jost, Eds., Physical Chemistry: An Advanced Treatise, vol. 10, Academic Press, San Diego, Calif, USA, 1976.

[37] S. M. Sze, Semiconductor Devices: Physics and Technology, John Willey \& Sons, New York, NY, USA, 1985.

[38] J. Maier and W. Göpel, "Investigations of the bulk defect chemistry of polycrystalline Tin(IV) oxide," Journal of Solid State Chemistry, vol. 72, no. 2, pp. 293-302, 1988.

[39] C. Malagù, V. Guidi, M. Stefancich, M. C. Carotta, and G. Martinelli, "Model for Schottky barrier and surface states in nanostructured $n$-type semiconductors," Journal of Applied Physics, vol. 91, no. 2, pp. 808-814, 2002.

[40] M. Akiyama, H. Tamaki, N. Miura, and N. Yamazoe, "Tungsten oxide-based semiconductor sensor highly sensitive to NO and $\mathrm{NO}_{2}$," Chemistry Letters, vol. 1991, pp. 1611-1614, 1991.

[41] Y.-G. Choi, G. Sakai, K. Shimanoe, N. Miura, and N. Yamazoe, "Wet process-prepared thick films of $\mathrm{WO}_{3}$ for $\mathrm{NO}_{2}$ sensing," Sensors and Actuators B, vol. 95, no. 1-3, pp. 258-265, 2003.

[42] C. Xu, J. Tamaki, N. Miura, and N. Yamazoe, "Grain size effects on gas sensitivity of porous $\mathrm{SnO}_{2}$-based elements," Sensors and Actuators B, vol. 3, no. 2, pp. 147-155, 1991. 

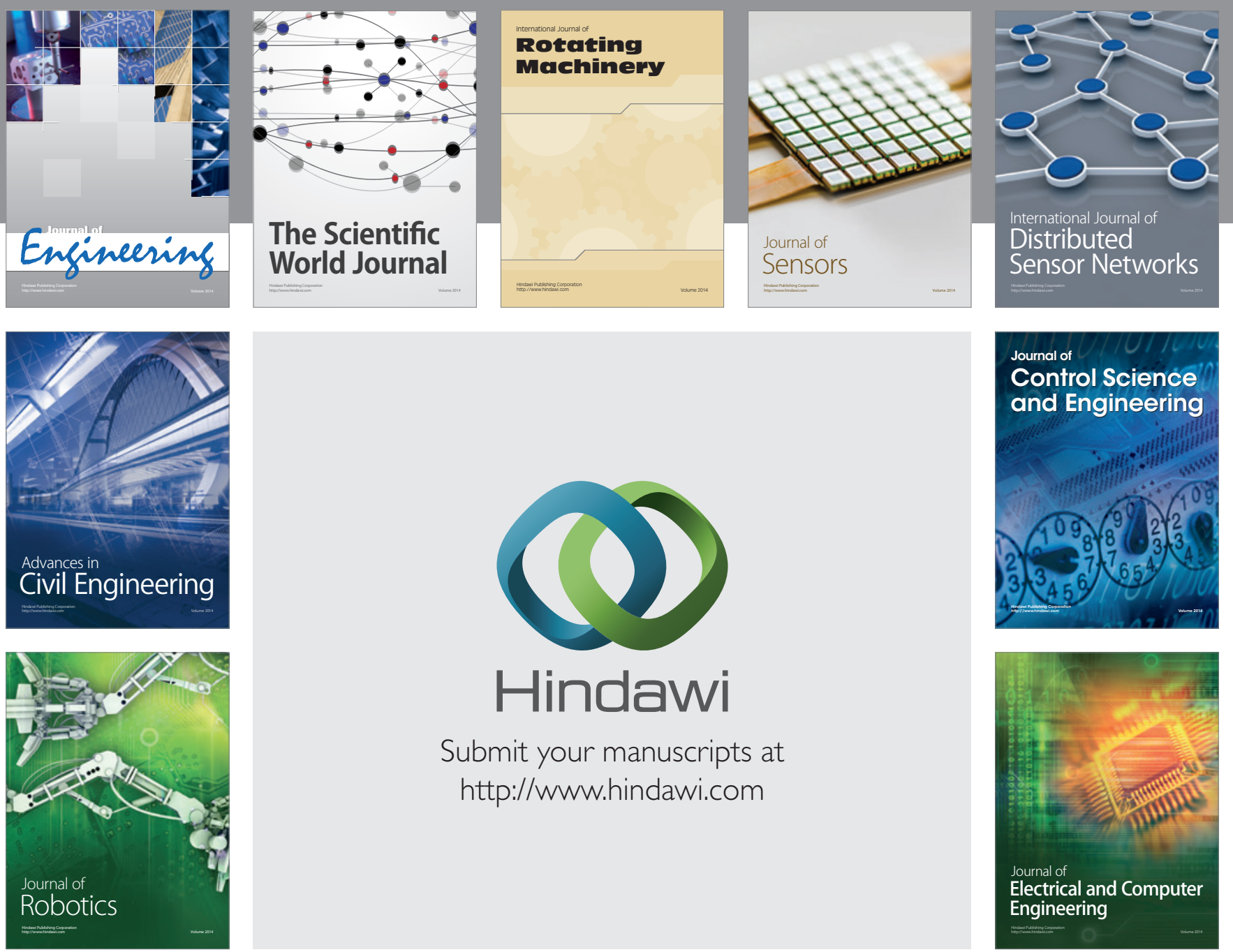

Submit your manuscripts at

http://www.hindawi.com
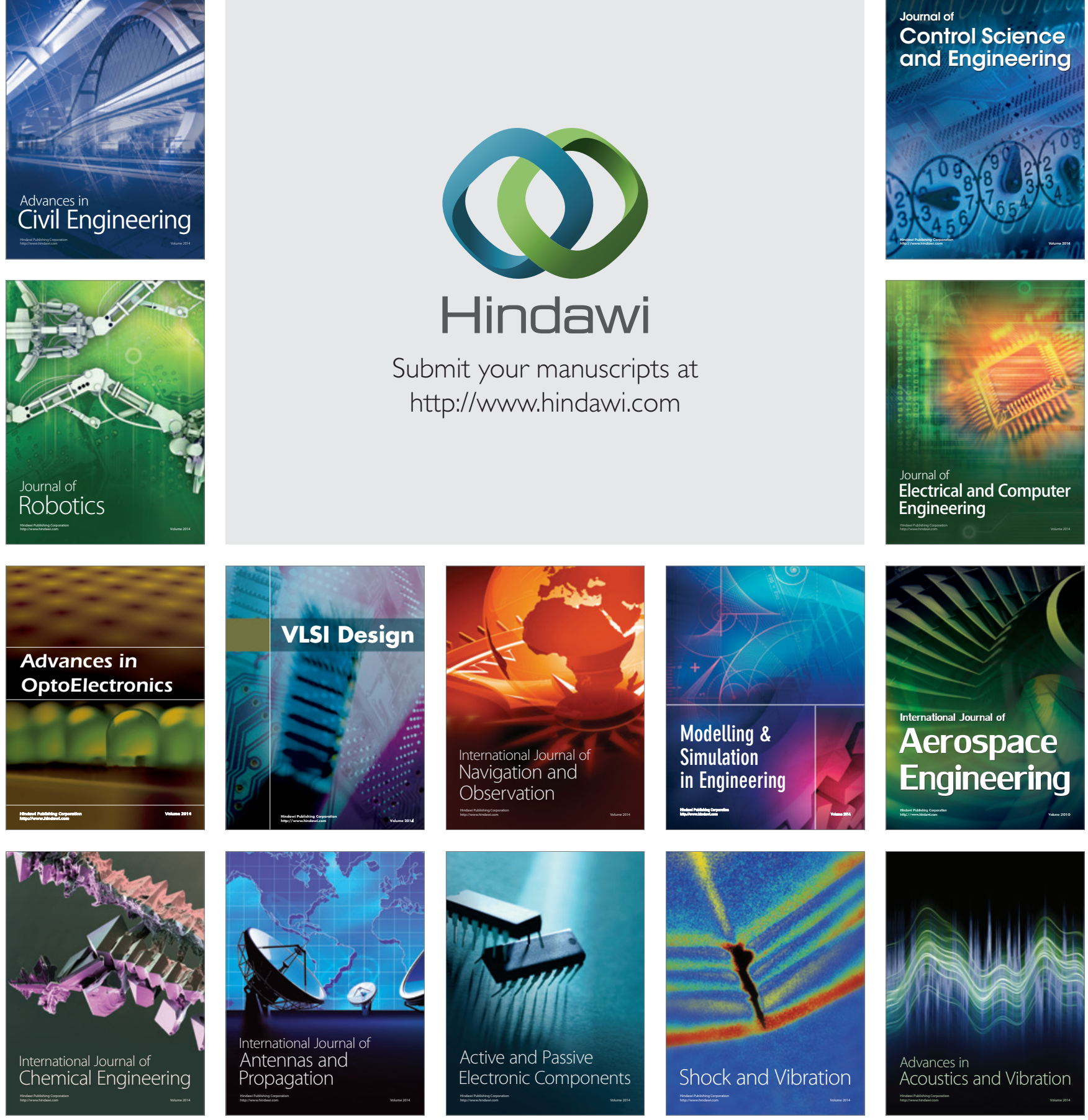